\title{
Article
}

Subscriber access provided by EKU Libraries

\section{Oxygen reduction on platinum surfaces in acid media: Experimental evidence of a CECE/DISP initial reaction path}

\author{
Ana Maria Gomez-Marín, Juan M. Feliu, and Edson A. Ticianelli
}

ACS Catal., Just Accepted Manuscript • DOI: 10.1021/acscatal.8b03351 • Publication Date (Web): 25 Jan 2019

Downloaded from http://pubs.acs.org on January 26, 2019

\section{Just Accepted}

"Just Accepted" manuscripts have been peer-reviewed and accepted for publication. They are posted online prior to technical editing, formatting for publication and author proofing. The American Chemical Society provides "Just Accepted" as a service to the research community to expedite the dissemination of scientific material as soon as possible after acceptance. "Just Accepted" manuscripts appear in full in PDF format accompanied by an HTML abstract. "Just Accepted" manuscripts have been fully peer reviewed, but should not be considered the official version of record. They are citable by the Digital Object Identifier (DOI®). "Just Accepted" is an optional service offered to authors. Therefore, the "Just Accepted" Web site may not include all articles that will be published in the journal. After a manuscript is technically edited and formatted, it will be removed from the "Just Accepted" Web site and published as an ASAP article. Note that technical editing may introduce minor changes to the manuscript text and/or graphics which could affect content, and all legal disclaimers and ethical guidelines that apply to the journal pertain. ACS cannot be held responsible for errors or consequences arising from the use of information contained in these "Just Accepted" manuscripts. 


\title{
Oxygen reduction on platinum surfaces in acid media: Experimental evidence of a CECE/DISP initial reaction path
}

\author{
Gómez-Marín, Ana M.,2,*, Feliu, Juan M.,3,*, Ticianelli, Edson ${ }^{1}$ \\ ${ }^{1}$ Instituto de Química de São Carlos, Universidade de São Paulo, Caixa Postal 780, Fisico \\ Quimica, Av. Trabalhador Sao Carlense, São Carlos CEP 13560-970, SP, Brazil. \\ ${ }^{2}$ Department of Chemistry, Division of Fundamental Sciences (IEF), Technological \\ Institute of Aeronautics (ITA), São José dos Campos CEP: 12228-900, SP, Brazil. \\ ${ }^{3}$ Instituto de Electroquímica, Universidad de Alicante, Apt 99, E-03080 Alicante, Spain. \\ *E-mail: agomezma@ita.br(A.M. Gómez-Marín), juan.feliu@ua.es (J.M. Feliu).
}

\begin{abstract}
In this work, a detailed kinetic analysis of the oxygen reduction reaction (ORR) on platinum is performed by applying steady and non-steady state methodologies at stationary and rotating disk electrodes, and comparing experimental results to calculated curves via digital simulations. Results reveal the existence of a complex chemical-electrochemicalchemical-electrochemical initial reaction sequence, a CECE-mechanism, and the possible contribution of a parallel disproportionation process in acid media during the reaction. Under convection-controlled circumstances, the first charge transfer step would be the ratedetermining step (RDS) on bulk electrodes, in agreement with early reports, but at different working conditions other initial steps can become the RDS. Additionally, contrary to the current accepted view, results support the formation of a soluble intermediate in the initial, and fast, chemical reaction, with a short lifetime, compatible with the formation of either the hydroperoxyl radical, $\mathrm{HO}_{2}{ }^{*}$, or superoxide anion, $\mathrm{O}_{2}^{-}$, followed by a fast protonation. In light of present results, possible mechanisms, including the oxidation of $\mathrm{H}_{2} \mathrm{O}_{2}$ that could be produced either by disproportionation or reduction of $\mathrm{HO}_{2}{ }^{*}$, and/or $\mathrm{O}_{2}^{-}$, radicals are discussed. This interrelated reaction scheme would be the principal cause of large ORR overpotentials but, at the same time, it would open the opportunity for designing alternative catalysts beyond fundamental limits imposed by the apparent scaling relations between reaction intermediates, such as $\mathrm{OH}_{\text {ads }}, \mathrm{O}_{\text {ads }}$, and $\mathrm{HO}_{2, \text { ads }}$ adsorbates.
\end{abstract}

Keywords: cyclic voltammetry, reaction mechanism, scan rate study, oxygen reduction, digital simulations, mass-transport effects, rotating disk electrodes. 


\section{Introduction}

The oxygen reduction reaction (ORR) is a cornerstone process in electrochemistry and sustainable energy technologies. It is a complex reaction that includes several steps and different possible intermediates species. Then, after decades of research, the reaction still occurs with large energy losses and molecular details of the mechanism are rather unknown, even on platinum, the best pure metal electrocatalyst [1-8]. In this case, it is known that oxygen mainly reduces to water both in acid and alkaline solutions, apparently along two parallel pathways $[1,9,10,11-16]$. A direct route, without detection of intermediates species, Eqn. (1), and a consecutive, serial path, with hydrogen peroxide as intermediate, Eqn. (2), that undergoes a further reduction [14-16], Eqn. (3).

$$
\begin{gathered}
\mathrm{O}_{2}+4 \mathrm{H}^{+}+4 e^{-} \rightleftarrows 2 \mathrm{H}_{2} \mathrm{O} \\
\mathrm{O}_{2}+2 \mathrm{H}^{+}+2 e^{-} \rightleftarrows \mathrm{H}_{2} \mathrm{O}_{2} \\
\mathrm{H}_{2} \mathrm{O}_{2}+2 \mathrm{H}^{+}+2 e^{-} \rightleftarrows 2 \mathrm{H}_{2} \mathrm{O}
\end{gathered}
$$

A recent study under transient conditions and different timescales in acid media has evidenced a more complex scheme, in which both inner- and outer-sphere reactions occur, together to the parallel formation of certain amount of $\mathrm{H}_{2} \mathrm{O}_{2}$, regardless the main mechanism. $\mathrm{H}_{2} \mathrm{O}_{2}$ would appear well because of disproportionation, Eqns. (4) and/or (5), or reduction, Eqn. (6), of soluble hydroperoxyl radicals, $\mathrm{HO}_{2}{ }^{\bullet}$, intermediates formed in an initial chemical step during the ORR on Pt surfaces [17]. Production of adsorbed $\mathrm{HO}_{2}{ }^{\bullet}, \mathrm{HO}_{2 \text {,ads, or }}$ superoxide, $\mathrm{O}_{2 \text {,ads }}{ }^{-}$, radicals during the $\mathrm{ORR}$ has been already reported to occur at $\mathrm{Pt}(111)$ [18-22], and polycrystalline Pt, Pt(poly), electrodes [23-25].

$$
\begin{gathered}
2 \mathrm{HO}_{2}^{*} \rightleftarrows \mathrm{H}_{2} \mathrm{O}_{2}+\mathrm{O}_{2} \\
\mathrm{O}_{2}^{-}+\mathrm{HO}_{2}^{*} \rightleftarrows \mathrm{HO}_{2}^{-}+\mathrm{O}_{2} \\
\mathrm{HO}_{2}^{*}+\mathrm{H}^{+}+e^{-} \rightleftarrows \mathrm{H}_{2} \mathrm{O}_{2}
\end{gathered}
$$

Additionally, an analysis of the change in ORR peak currents, $j_{p}{ }^{O R R}$, in linear sweep voltammograms (LSVs) as a function of the scan rate, $v$, at stationary and rotating disk electrodes, RDEs, evidenced a levelling of reduction currents with increasing $v$ beyond a threshold value that depends on the rotation rate, $\omega[17]$. Hence, $j_{p}{ }^{O R R}$ 's are not proportional to $\sqrt{ } v$, contrarily to what it is expected from Randles-Ševčík equations for fast, Eqn. (7a), or slow, Eqn. (7b), charge transfers [26], or overall $n$-electron processes with a first electron transfer as rate-determining step (RDS) [26-34], as usually reported for the ORR [1,9,10,14$16,35,36]$. 


$$
\begin{aligned}
& j_{p}=0.446 n F A C_{O}^{0}\left(\sqrt{\frac{n_{a} F D v}{R T}}\right) \\
& j_{p}=0.496 n F A C_{O}^{0}\left(\sqrt{\frac{\alpha n_{a} F D v}{R T}}\right)
\end{aligned}
$$

with $n$, the total number of transferred electrons; $n_{a}$, the number of transferred electrons in the RDS (usually one); $F$, the Faraday's constant; $A$, the electrode geometric area; $C^{0}{ }_{O}$ and $D$ the solubility and the diffusivity coefficient of the reactant in the electrolyte, respectively; $\alpha$, the transfer coefficient; $R$, the ideal gas constant and $T$ the temperature.

Currents in LSVs independent of $v$ at scan rates faster than a certain threshold value are called "kinetic currents" and indicate that the electrochemical reaction is controlled by a chemical process instead of a charge transfer [28,31]. The dynamics appears at scan rates with an equivalent characteristic time, $\tau_{v}$, (i.e. the time during which a stable electroactive species can communicate with the electrode [26]) shorter than the magnitude of the time scale of the chemical reaction [28,31,33,34]. Hence, reported levelling of reduction currents at fast scan rates during the ORR at Pt surfaces would indicated the existence of a chemical step between two charge transfers.

The presence of a chemical reaction between two charge transfers during the ORR has also been suggested by studies at nanostructured Pt electrodes that indicate a significant effect of mass transfer conditions upon the final product distribution [37-42]. Apparently, the masstransport enhancement at nanoparticles $[26,39,42]$ induces a decrease in the effective number of transferred electrons, $n_{\text {eff }}$, from 4 to 2 , and a parallel increase in the amount of $\mathrm{H}_{2} \mathrm{O}_{2}$ detected, as the size of Pt nanoparticles decreases [37-42]. However, under those conditions, the increase in the $\mathrm{H}_{2} \mathrm{O}_{2}$ production does not undoubtedly imply the existence of a chemical reaction. Stronger adsorption of oxygen containing species at NPs $[43,44]$, or the presence of solution impurities in the electrolyte [14,15,45-48] could also account for the change in the measured product distribution.

In this work, following our previous study [17], the ORR on $\mathrm{Pt}($ poly) is investigated at different time scales at stationary electrodes and RDEs, to gain information about the reaction mechanism. Within this goal, LSVs are qualitatively analyzed by plotting experimental $j_{p}{ }^{\text {ORR' }}$ s in terms of the current function, $\Psi$, Eqn. (8) [26-34,49-54], at different $v^{\prime} \mathrm{s}$, and resulting curves are compared to classical diagnostic criteria for typical mechanisms involving kinetic complications already reported [26-34,49-54], and equivalent data from digital simulations.

$$
\Psi=\frac{j}{n F A C_{O_{2}}^{0} \sqrt{\frac{n_{a} F D v}{R T}}}
$$


Notice that at $j=j_{p}, \Psi_{p}$ from this equation is nothing else but the value of the proportionality constant in Eqns. (7), multiplied by $\sqrt{\alpha}$ in the case of irreversible electrochemical reactions.

Results expose the existence of two chemical steps in the main ORR route on Pt surfaces in acid at high potentials, one before and one after the first charge transfer, shedding light over initial mechanistic details of the reaction. Though, contrary to what has been already suggested, results also support the production of a soluble species in the first chemical step, different to $\mathrm{H}_{2} \mathrm{O}_{2}$, but that later may convert to $\mathrm{H}_{2} \mathrm{O}_{2}$, either in a subsequent or a parallel reaction, or simultaneously through both reaction schemes. Thus, first steps in the ORR mechanism would follow a CECE/DISP scheme and comprise both inner- and outer-sphere reactions [17]. Inside these results, plausible mechanisms are proposed and the implications in current strategies for designing ORR electrocatalysts and improving the durability of cathode catalyst layers of fuel cells are discussed.

\section{Experimental Section}

Electrochemical measurements were conducted at room temperature $(\mathrm{RT}), \sim 22{ }^{\circ} \mathrm{C}$, in a two-compartment, three electrodes, all-glass cell, using an Autolab (Nova) potentiostat/galvanostat equipped with an interchangeable rotating platinum disk electrode setup (Pine Instruments). Suprapure perchloric acid (Merck) was used to prepare aqueous solutions in ultrapure water (Purelab Ultra, Elga-Vivendi). $\mathrm{O}_{2}$ and $\mathrm{Ar}$ (N50, Air Liquid) were also employed. All potentials were measured against the Reversible Hydrogen Electrode (RHE) and a large, flame cleaned, Pt wire coil was used as a counter electrode. The stability of the voltammetric profiles with time was carefully checked to ensure solution cleanliness, especially during RDE experiments, due to the forced convection conditions.

A platinum disk $\left(5 \mathrm{~mm}\right.$ diam., $\left.0.196 \mathrm{~cm}^{2}\right)$, polished to a mirror finish before each experiment (0.3 $\mu \mathrm{m}$ alumina, Buehler), was employed. The electrode was left in concentrated sulfonitric solution at least $24 \mathrm{~h}$ before each experiment and later generously washed with ultrapure water. Inside the cell, the electrode was electrochemically treated by several consecutive anodic and cathodic pulses (60 s each) at 1.4 and $-0.25 \mathrm{~V}$, respectively, followed by voltammetric cycles between -0.25 and $1.15 \mathrm{~V}$ at $0.1 \mathrm{~V} \mathrm{~s}^{-1}$. This pretreatment was performed as many times as required until a stable and typical cyclic voltammogram (CV) was obtained between 0.05 and $1.15 \mathrm{~V}$ after the treatment, similar to the one given in Figure $\mathrm{S} 1 \mathrm{~B}$. The electrode roughness factor, i.e. the ratio between the electrochemical active surface 
area and the geometric area of the electrode, was between $\sim 1.2$ and 1.3, calculated from the $\mathrm{CV}$ in Ar-saturated $0.1 \mathrm{M} \mathrm{HClO}_{4}$ solutions and by considering one adsorbed monolayer being equal to $\sim 0.200 \mathrm{mC} \mathrm{cm}^{-2}[55,56]$.

Besides, because transient experiments are very sensitive to initial conditions [17], a conditioning program before each experiment, similar to previous studies [17,57,58], was applied to the electrode in order to get quantifiable and reproducible data. The procedure is given in Figure S1A, and it comprised sweeping the electrode between 1.15 and $-0.05 \mathrm{~V}$ at $0.5 \mathrm{~V} \mathrm{~s}^{-1}$ five times, beginning from the open circuit potential $(\mathrm{OCP})$ in a $\mathrm{O}_{2}$-saturated $0.1 \mathrm{M}$ $\mathrm{HClO}_{4}$ solution, $\sim 1.02 \mathrm{~V}$, in the positive-going direction. This procedure assures that the electrode surface is in a similar state before every measurement.

In situ $\mathrm{iR}$ drop corrections were made to compensate the electrolyte resistance when necessary [26], and the quality of the iR compensation was assessed by following the position of the characteristic peaks corresponding to the hydrogen adsorption/desorption in the CVs. It is known that the position of these peaks is practically constant up to scan rates as high as $10 \mathrm{~V} \mathrm{~s}^{-1}$ [59]. Initially, the value of the uncompensated resistance, $R_{u}$, was determined by using a current interruption procedure at each $v$ in $\mathrm{O}_{2}$ free solutions. Then, the value was refined by employing the positive feedback procedure and taking CVs at increasing values of $R_{u}$ until the current signal began to oscillate, in an iterative, trial-and-error approach. During measurements, the compensated resistance was usually set to about $85-95 \%$ of the estimated value of $R_{u}$ (the value of $R_{u}$ just before the systems began to oscillate, $\sim 10<R_{u}<$ $25 \Omega$ depending on $v$ ). Finally, the solution was saturated with $\mathrm{O}_{2}$ and CVs were taken by employing the same $R_{u}$ value than in $\mathrm{O}_{2}$-free solutions at each $v$. Under these conditions, the maximum expected error in the value of the half-peak potential of the ORR, $E_{p / 2}{ }^{O R R}$, at $10 \mathrm{~V}$ $\mathrm{s}^{-1}$ is $\sim 5 \mathrm{mV}$, and at $5 \mathrm{~V} \mathrm{~s}^{-1} \sim 3 \mathrm{mV}$. Lower values are expected at slower $v$, because this error decreases proportionally to the value of $E_{p / 2} O R R$.

Additionally, to provide a qualitative understanding of experimental results, LSVs at stationary electrodes and RDEs of discussed mechanisms in the text were calculated by digital simulation with the general-purpose, commercial software COMSOL Multiphysics 5.1. For this purpose, both reversible and irreversible charge transfers were considered and proposed reaction schemes included chemical reactions inside the description. Details regarding the implementation can be found in the software's reference manual and modules' user guides. 
For mathematical simplicity, model simulations at RDEs consider diffusion equations based on the Nernst model and the resulting system was solved numerically for describing LSVs [60-64]. Under this model, all transient processes are assumed to take place within a thin layer bonded to the electrode surface, the Nernst diffusion layer, with a thickness $\delta_{\text {diff }}$. Outside this layer, a fixed concentration for all species is assumed: $C\left(x=\delta_{\text {diff }}\right)=0$ for all products, and $C\left(x=\delta_{d i f f}\right)=C^{0}{ }_{O}$ for the reactant. The thickness of the steady-state diffusion layer at any rotation rate was calculated by employing the Levich approximation $[26,65]$, and it is given by

$$
\delta_{\omega}=1.612 D^{1 / 3} \mathrm{v}^{1 / 6} \omega^{-1 / 2}
$$

where $\mathrm{v}$ is the kinematic viscosity of the electrolyte, which for $0.1 \mathrm{M} \mathrm{HClO}_{4}$ it has a value of $\left.\mathrm{v}=0.01009 \mathrm{~cm}^{2} \mathrm{~s}^{-1}[45]\right)$.

Simulations have been performed with successive mesh refinement until no appreciable changes in the LSVs were calculated. Additionally, because of the existence of thin reaction layers close to the electrode surface when including chemical reaction into the mechanism [66], two unequal intervals were employed to describe the geometry of the system, each one simulated with a different mesh size. The first interval, adjacent to the electrode surface had the smallest grid, and goes from $x=0$ to $x=10 \mu \mathrm{m}$, while the second one comprises the length from $x=10 \mu \mathrm{m}$ to $x=\delta_{\text {diff, }}$, to guarantee the precise resolution of the phenomena close to the surface. Besides, for improving convergence, the Jacobian was updated on every iteration, the maximum number of iterations increased until 25 and a tolerance factor of at least 0.1 set (for a minimum relative tolerance of 0.001 ), when necessary. Details regarding the mathematical structure of the model, as well as employed boundary conditions are given as supporting information. In addition, data related to the implementation of the model in COMSOL Multiphysics 5.1 are also provided.

The induced error by considering the Nernst model instead of rigorously solving the convective-diffusive equations has been already calculated and reported to be not greater than $4 \%$, when peak currents in LSVs of single reversible, irreversible, or quasi-reversible electron transfers are estimated at RDEs [67]. In addition, as reported previously [17], simulated curves at stationary and RDE electrodes for all analyzed mechanisms superimpose if all participating species have equal diffusion coefficients, supporting the idea regarding a low induced error by applying the Nernst model for describing transient curves at RDEs. 


\section{Results and Discussion}

Once the cleaning procedure was performed, the electrode was characterized in Arsaturated $0.1 \mathrm{M} \mathrm{HClO}_{4}$, and then the solution was saturated with $\mathrm{O}_{2}$. Next, right after applying the conditioning procedure for each scan rate, cyclic voltammograms (CVs) at different scan rates at stationary electrodes and RDEs were taken. In these experiments, the upper limit potential, $E_{u p}$, was set to $1.15 \mathrm{~V}$, a value that guarantees a constant electrochemical surface active area (ECSA) [56,68], and a surface coverage only composed by $\mathrm{OH}_{\mathrm{ads}}$ and/or $\mathrm{O}_{\mathrm{ads}}$, instead of a true oxide phase [68], as it has been previously discussed [17].

\subsection{Steady and non-steady state polarization curves for the ORR on Pt surfaces}

Figure 1 shows linear voltammetry scans (LSVs), after background subtraction, under steady-state and transient conditions for the oxygen reduction reaction on $\mathrm{Pt}($ poly) at two different rotation rates, $\omega=1000$ and $1600 \mathrm{rpm}$. Measured voltammetry data without background subtraction, are given in Figure S2. As commonly reported, ORR steady-state polarization curves at bulk electrodes are characterized by sigmoidal, S-shaped curves, typical for convection-driven electrochemical processes, reaching a limiting current, $j_{\text {lim }}$, once the reaction is controlled by the mass-transfer, at $E<\sim 0.75 \mathrm{~V}$, curves a to c in Fig. 1 . In absence of any kinetic complications, the value of $j_{l i m}$ is proportional to square root of $\omega$, and it can be theoretically calculated by employing the Levich equation, Eqn. (10), $[26,28,30,61-65,67,69]$,

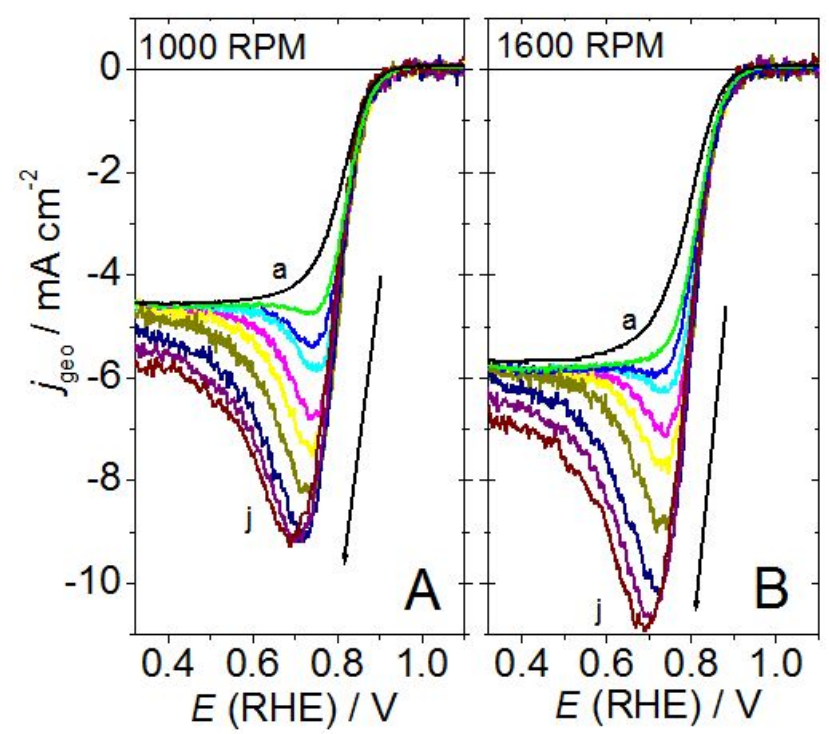

Figure 1: Background-subtracted negative-going scans at 1000 (A) and $1600 \mathrm{rpm}$ (B) for the oxygen reduction on $\mathrm{Pt}$ (poly) in $\mathrm{O}_{2}$-saturated $0.1 \mathrm{M} \mathrm{HClO}_{4}$ solutions after conditioning 
the electrode and two subsequent cyclic voltammograms. Scan rates are a) 0.1 ; b) 0.5 ; c) 0.8 ; d) 1.0 ; e) 1.5 ; f) 2.0 ; g) 3.0 ; h) 5.0 ; i) 7.0 ; j) $10 \mathrm{~V} \mathrm{~s}^{-1}$. Arrows indicate increasing scan rates.

$$
j_{l i m}=n_{e f f} F A C_{O_{2}}^{0} \frac{D}{\delta_{\omega}}
$$

where $\delta_{\omega}$ can be described by Eqn. (9). Then,

$$
j_{\text {lim }}=0.62 n_{e f f} F A D^{2 / 3} \mathrm{u}^{-1 / 6} C_{O_{2}}^{0} \omega^{1 / 2}
$$

From polarization curves at different $\omega$, and the plot of $j_{\text {lim }}$ vs. $\omega^{1 / 2}$ (a Levich plot), as it is seen in Figure S3, the ORR at Pt(poly) follows Eqns. (10), as usually reported [1-10,1821,34-38,45,46,70-75]. Classical kinetic analysis of these polarization curves evidences a change in the Tafel slope in the positive-going scan from $\sim 120$ to $\sim 60 \mathrm{mV}$ at high and low current densities, respectively [1-10,18-21,34-38], calculated from a plot of the logarithm of kinetic currents as function of the applied potential, as it is seen in Fig. S3A. Additionally, this analysis also indicates a first-order dependence relative to the $\mathrm{O}_{2}$-concentration, as suggested by the good lineal fitting of the Levich plot, shown in Fig. S3B.

Differences at low $(E<0.35 \mathrm{~V})$ and high potentials $(E>0.7 \mathrm{~V})$ between direct and reverse scans in Fig. S3 are typical of the ORR at Pt surfaces [9-11,20,45,57]. At $E<0.35 \mathrm{~V}$, the difference appears due to the adsorption/desorption of hydrogen in this region (nonbackground subtracted CVs), besides the parallel detection of $\mathrm{H}_{2} \mathrm{O}_{2}$. Because of that, it has been classically assumed that $\mathrm{H}_{\text {ads }}$ either inhibits the $\mathrm{O}-\mathrm{O}$ bond scission, or blocks reactive surface sites $[14,15,18,45]$. Recently, it has been shown that this inhibition of $\mathrm{H}_{2} \mathrm{O}_{2}$ reduction can be better explained by considering the interface water reorganization and the potential of zero free charge of the metal surface [76]. At $E>0.7 \mathrm{~V}$, differences between positive- and negative-going scans are typically explained in terms of different ORR mechanisms in oxidefree and oxide-covered Pt surfaces [9-11,45]. The lower ORR activity in the negative-going scan, relative to the positive-going direction, has been attributed to a poisoning role of oxygen-containing species adsorbed on the Pt surface [2-5,37,45,57,70,71].

In contrast, as recently highlighted [17], the analysis of non-steady state LSVs reveals a different picture. Simple one-electron transfers, or overall $n$-electron processes with a first electron transfer as RDS [26-34] as typically accepted for the ORR [1,9,10,14-16,35,36], under transient conditions are characterized by current peaks, $j_{p}$, proportional to $\sqrt{ } v$, Eqns. (7), regardless the electrode hydrodynamic condition, stationary or RDE $[60-64,67,69]$. However, transient LSVs in Fig. 1 ACS Paragon characterized by current peaks, $j_{p}{ }^{O R R}$, around $\sim 0.7$ to 
$0.8 \mathrm{~V}$ depending of the scan rate, whose magnitude increases by increasing $\omega$. Compare for example $j_{p}$ ORR's at 1000 and $1600 \mathrm{rpm}$ at a fixed $v$ in Fig. 1.

The dependence of $j_{p}{ }^{O R R}$ on $\omega$ is clearly evident in a plot of the normalized peak current density, $i_{p}{ }^{O R R} / n F A C^{0}{ }_{O} \sqrt{ } D_{O_{2}}$ against the normalized square root of the scan rate, $\left(\sqrt{\frac{n_{a} F v}{R T}}\right)$, as it is shown in Figure 2A. This figure was calculated by considering the $D_{O_{2}}=1.93 \times 10^{-5} \mathrm{~cm}^{2} \mathrm{~s}$; $C^{0} O_{2}=1.26 \mathrm{mM}$; and $n=n_{a}=1$. Besides, for the sake of comparison, theoretical curves for simple one, $n=1$, and four, $n=4$, fast and slow ( $\alpha=0.5)$ total electron transfers are also given. Note that the value of the normalized $j_{p} O R R$ at stationary electrodes is rather constant with $v$, and much lower than expected for a 4-electron transfer. Instead, at RDEs $j_{p}$ ORR strongly depends on $v$ and $\omega$, and after a threshold value of the scan rate is reached, current peaks practically become constant with $v$, but not $\omega$, and lower than for a 4-electron transfer.
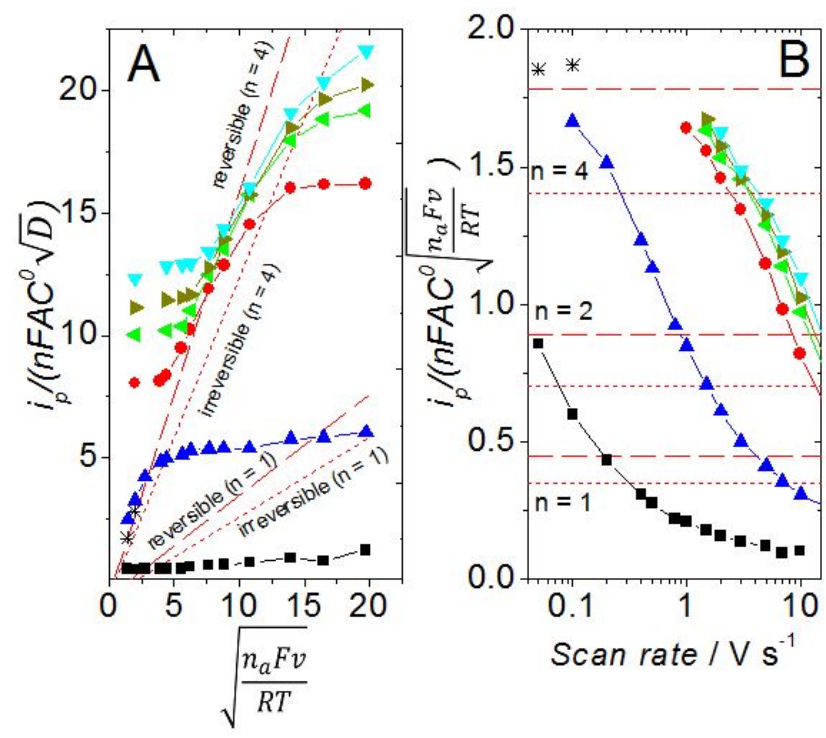

Figure 2: Normalized peak currents, $j_{p} / n F A C^{0} \mathrm{O}_{2} \sqrt{ } D_{\mathrm{O}_{2}}$, against the square root of the normalized scan rate, $\sqrt{\frac{n_{a} F v}{R T}}$, for continuous LSVs during the oxygen reduction at $\mathrm{Pt}($ poly) at RDEs: $70(\triangle) ; 1000(\bullet) ; 1600(\triangleleft) ; 2000(\triangleright)$; and 2500 rpm ( $)$ ), and stationary electrodes: (घ), and after the potential was held at $1.02 \mathrm{~V}$ for $150 \mathrm{~s}$ before taking the LSV (ж) [17] (A). Variation of the peak current function, $\Psi_{p} O R R$, with $v(\sigma>10)$. Data were taken from background-subtracted, negative-going LSVs after conditioning the electrode and two subsequent CVs, as in Fig. 1 (B). Theoretical curves for simple reversible (dashed) and irreversible, $\alpha=0.5$, (dotted) charge transfers ( $n=1$ and 4$), \Psi_{p}{ }^{0}$, and for $E_{1} C E_{2^{-}}(\mathrm{n}=2)$ and $E_{1} C E_{3}$ - mechanisms $(\mathrm{n}=4), \Psi_{p} E_{1} C E_{3}$, in stationary electrodes are also given. 
Contrarily, according to Eqns. (7) for transient systems, a plot of normalized peak current density against the normalized square root of the scan rate, as the one in Fig. 2A, for a simple electron transfer reaction at stationary electrodes without any kinetic complication should follow a straight line, with a zero intercept (dashed lines in Fig. 2A). The value of the slope of this plot depends on the reversibility degree of the charge transfer and it is given by the proportionality constant in Eqns. (7): 0.446, or $0.351(\alpha=0.5)$ for simple fast, Eqn. (7a), or slow, Eqn. (7b), charge transfers, respectively [26-33,49,54].

Analogously, at RDEs under transient conditions numerical simulations have shown that $j_{p} O R R$ is close to the value reached by stationary electrodes, at normalized scan rates equivalent to a time scale, at least, ten times lower than the characteristic time at RDEs, given by $\frac{\delta_{\omega}^{2}}{D}[26]$, regardless $\omega[61-64,67,69]$. This condition can be better described in terms of the parameter $\sigma$, given by Eqn. (11),

$$
\sigma=\frac{n_{a} F v \delta_{\omega}^{2}}{R T D}>10
$$

with $\delta_{\omega}$ described by Eqn. (9). Theoretical and experimental slopes in this case are between 0.395 to 0.446 for fast (reversible) and 0.302 to $0.351(\alpha=0.5)$ for slow (irreversible) electron transfers, depending on the mathematical approximation employed to solve the set of differential equations for describing electrochemical systems at RDE's [61$64,67,69]$. For $\sigma<10$, the system is controlled either by convection or by mixed convectiondiffusion, and curves either lack of a current peak, i.e. S-shaped curves, or normalized current peaks are slightly larger than at stationary electrodes [61-64,67,69].

As previously discussed [17], the constant value of $j_{p}{ }^{O R R}$ regardless $v$ in Fig. 2A reveal the existence of a chemical reaction inside the ORR mechanism that controls the process at those values of $v$. Under this condition, the experiment finishes before the chemical reaction could take place at full extent and currents are lower than expected for a $4 \mathrm{e}$ - transfer, and independent of $v$. Nevertheless, if the electrode potential is initially held for enough time at a potential higher than the reaction onset, $E_{\text {onset }} O R R$, the system behaves like an almost $4 \mathrm{e}^{-}$ transfer process at slow $v$, as it is evidenced by (ж) points in Fig. $2 \mathrm{~A}$ at 0.05 and $0.1 \mathrm{~V} \mathrm{~s}^{-1}$. Additionally, it appears that the dynamic of the chemical reaction depends on $\omega$, because a constant $j_{p}{ }^{O R R}$ regardless $v$ is reached at smaller values of $v$ at slow $\omega$ 's.

The complex ORR dynamics just described is easily evidenced by presenting the data in terms of the current function, $\Psi^{O R R}$, as a function of $v$ Eqn. (8), at different rotation rates, as it is given in Figure 3. From this graph, it is clear that the magnitude of $\Psi^{O R R}$ decreases at 
faster $v$, and this change also varies with $\omega$. Curves were calculated by considering $D_{O_{2}}$ and $\mathrm{C}^{0} \mathrm{O}_{2}$ values given above, and $n$, and $n_{a}=1$.

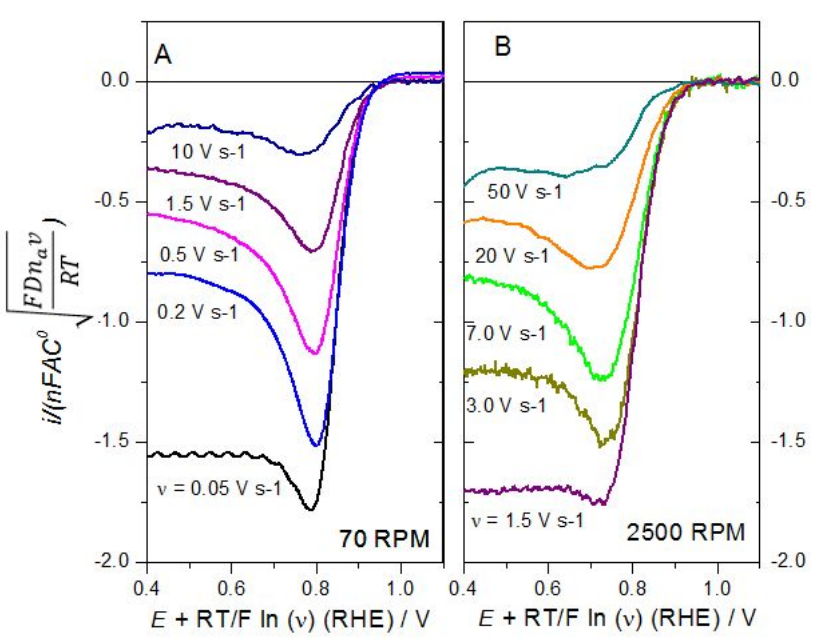

Figure 3: Current function from background-subtracted negative-going voltammograms at 70 (A) and $2500 \mathrm{rpm}$ (B) for the oxygen reduction on $\mathrm{Pt}$ (poly) in $\mathrm{O}_{2}$-saturated $0.1 \mathrm{M} \mathrm{HClO}_{4}$ solutions after conditioning the electrode and two subsequent cyclic voltammograms.

A qualitatively analysis of curves in Fig. 3 can be performed by considering only the change in current peaks, $\Psi_{p} O R R$, with $v$, as it is shown in Fig. $2 \mathrm{~B}$, and comparing experimental data to diagnostic criteria for complex mechanisms described in the literature [26-33,49-54]. In Fig. 2B, only data from curves for RDEs at scan rates and $\omega$ values for which $\sigma>10$ are presented, since only fo these conditions a similar change in $\Psi O R R$ with $v$ at stationary and RDEs has been confirmed, Eqns. (8) [61-64,67,69]. Curves in Fig. 2B were calculated by considering $D_{\mathrm{O}_{2}}, C^{0} \mathrm{O}_{2}, n$, and $n_{a}=1$ as described before. Dashed and dotted horizontal lines in this figure correspond to expected $\Psi_{p}{ }^{0}$ values at stationary electrodes calculated from Eqns. (7). For simple reversible and irreversible charge transfers, $\Psi_{p}{ }^{0}$ is equal to 0.446 and 0.351 , considering $\alpha=0.5(0.496 \sqrt{ } 0.5)$, respectively, which are independent of $v$. At RDEs reported $\Psi_{p}{ }^{0}$ are between 0.395 to 0.446 and 0.302 to 0.351 for reversible and irreversible electron transfers, respectively [61-64,67,69].

From Fig. 2B it is clear that $\Psi_{p}{ }^{O R R}$ 's are not constant with $v$. At slow $v, \Psi_{p} O R R$ at stationary electrodes and RDEs are close to $\Psi_{p}{ }^{0}$ 's for a $2 \mathrm{e}^{-}$and $4 \mathrm{e}^{-}$charge transfer, respectively, but, as $v$ increases, $\Psi_{p}{ }^{O R R}$ decreases and can reach values even lower than $\Psi_{p}{ }^{0}$ for a $1 \mathrm{e}^{-}$charge transfer at stationary electrodes, and RDEs at slow $\omega$. Under this circumstance, $\Psi^{O R R}$ curves become more spread out in the potential axis, but still share the same $E_{\text {onset }}$ ORR until a threshold value of $v$ is reached, depending on $\omega$, as it is seen ip Fig 3 . With an additional increase in $v, \Psi^{O R R}$ 's 
curves shift toward less positive potentials even more, not having now the same $E_{\text {onset }} O R R$, and drawn out even further, practically losing the peak potential, $E_{p} O R R$, at the fastest scan rates in Fig 3B. This is the point in which $\Psi_{p}{ }^{O R R}$ 's in Fig. $2 \mathrm{~B}$ reach values even smaller than $\Psi_{p}{ }^{0}$ for a $1 \mathrm{e}^{-}$charge transfer.

\subsection{A chemical step before the first charge transfer}

As it was recently discussed $[17,18,20]$, the $\omega$-dependence of $j_{p}{ }^{O R R}$ in Figs. 1, 2 and 3 is consequence of kinetic effects in the ORR mechanism, which can only be explained by considering the existence of a diffusion layer close to the electrode surface dictated by a chemical instead of an electrochemical reaction. As demonstrated by digital simulations, at least two soluble species with different diffusion coefficients co-exist during the reduction of $\mathrm{O}_{2}$ [17]. Otherwise, if only one soluble species is present, or different ones with equivalent diffusion coefficients, changes in $\omega$ would result in comparable changes in $\delta_{\omega}$, Eqn. (9), and identical concentration profiles determined by the magnitude of $D$ under diffusional control, are anticipated [26]. Similarly, if all diffusion layers were governed by an electrochemical reaction, $j_{p}{ }^{O R R}$ 's would only depend on $v$ and not on $\omega$ under transient conditions [17], and $j_{p}{ }^{O R R}$ 's at RDEs and stationary electrodes would coincide, which it is not the case as evidenced in this work [60-64,67,69].

Digital simulations of LSVs for simple reaction schemes, with parameters similar to the experimental conditions, have suggested a possible mechanism for explaining the dependence of $j_{p}{ }^{O R R}$ on $\omega$ in Figs. 1, 2 and 3. It has been shown that this experimental result only can be reproduced by a mechanism considering a fast surface chemical reaction of a

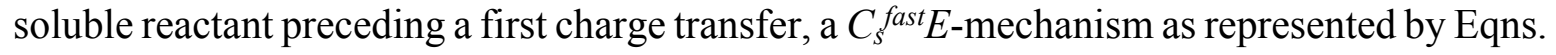
(12a) to (12c), giving rise to a soluble species with a lower diffusion coefficient than the reactant [17]. Note that the fact that this first chemical step is a surface reaction highlights the important electrocatalytic role of the surface, as suggest many year ago by Yeager [77,78]. An initial chemical step, Eqn. (12a), in the ORR mechanism is also evidenced by the decrease in $\Psi_{p}^{O R R}$ to values smaller than expected for a $1 \mathrm{e}^{-}$charge transfer in Fig. $2 \mathrm{~B}$, and the parallel disappearance of the peak current and the shift in $E_{\text {onset }}$ ORR to lower potentials at the fastest scan rates in Fig. 1A and Fig. 3.

$$
\begin{aligned}
& Z+M \stackrel{K}{\Leftrightarrow} M-A_{a d s} \\
& M-A_{a d s} \stackrel{K}{\Leftrightarrow} M+A \\
& A+n_{1} e^{-} \rightleftarrows B \\
& \text { ACS Paragon Plus Environment }
\end{aligned}
$$


Simulated curves for the mechanism given by Eqns. (12a) to (12c), considering a slow first charge transfer, and different diffusion coefficients between reagents and products at stationary electrodes and RDEs were calculated and results are given in Figures 4A and 4B. For the sake of comparison with experimental results in Fig. 2, changes in the normalized $j_{p}$, $i_{p} / n F A C^{0}{ }_{O 2} \sqrt{ } D_{O 2}$, against the square root of the normalized scan rate, $\sqrt{\frac{n_{a} F v}{R T}}$, and the peak current function, $\Psi_{p}^{\text {CsfastEirrev, }}$, as a function of $v$ are given in Fig. 4A and 4B, respectively. All curves were calculated by considering $\alpha=0.5$. For other values of $\alpha$ peak currents change proportional to $\sqrt{ } \alpha$, as dictated by Eqn. (7b), along with the proportional change in simulated Tafel slopes.
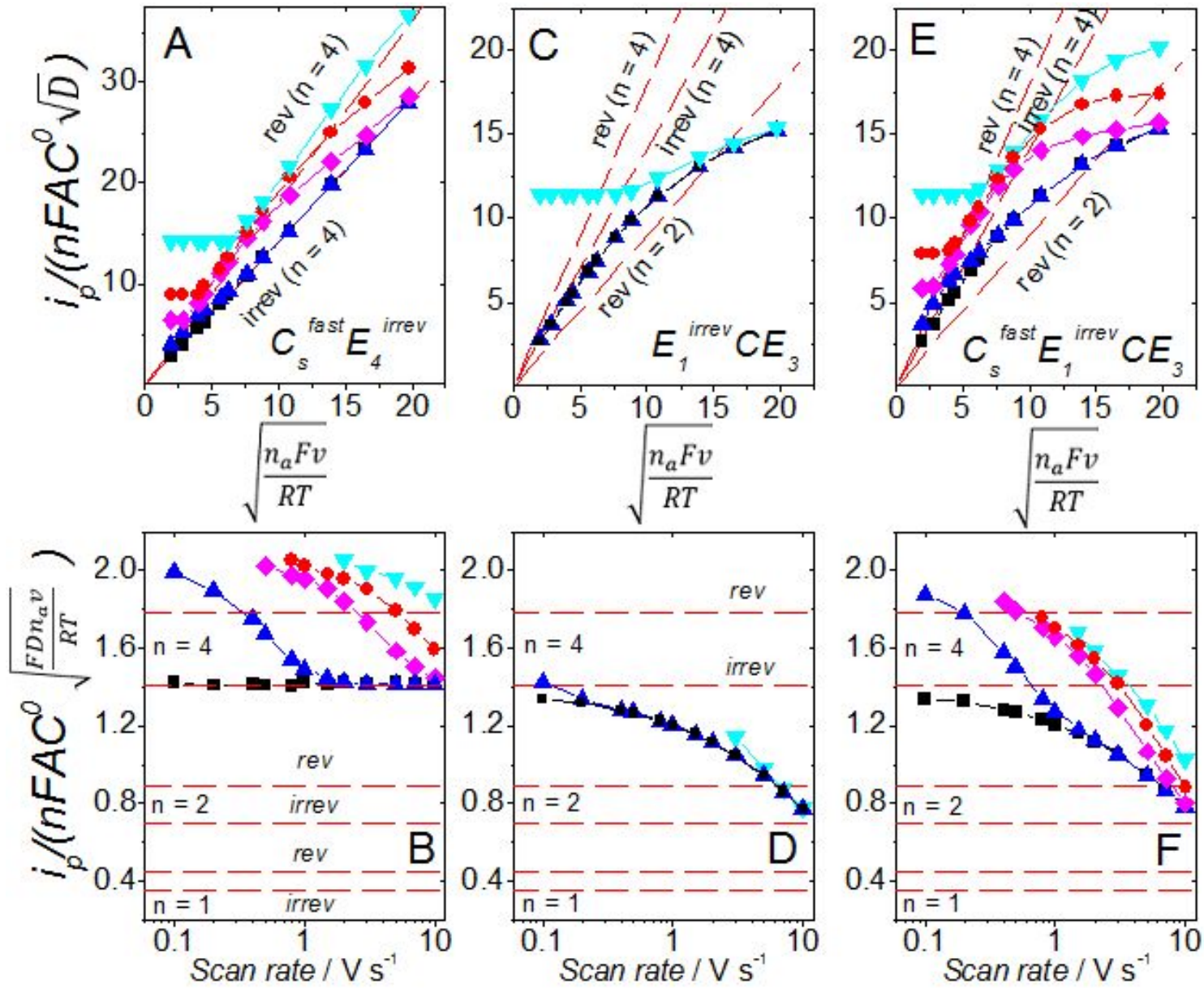

Figure 4: Normalized peak currents, $j_{p} / n F A C^{0}{ }_{2} \sqrt{ } D_{\mathrm{O}_{2}}$, against the square root of the normalized scan rate, $\sqrt{\frac{h_{a} F v}{R T}}$, from simulated linear sweep voltammograms (LSV's) of a first slow charge transfer at stationary and rotating disk electrodes. Symbols are the same as in

Fig. 2. (A) An irreversible surface chemical reaction of a soluble reactant producing a soluble species, $k_{\text {forward }}=1 \times 10^{7} \mathrm{M}^{-1} \mathrm{~s}^{-1}$, preceding a four-electron transfer, a $C_{s}^{\text {fast }} E_{4}^{\text {irrev }}$ mechanism. (C) A first-order chemical reaction, $k=1 \times 10^{2} \mathrm{~s}^{-1}$, between a first $1 \mathrm{e}^{-}$and a 
second $3 \mathrm{e}^{-}$charge transfers with $E_{1}{ }^{\circ}<E_{2}{ }^{\circ}$ (only one peak in the LSV), an $E_{1}{ }^{\text {irrev }} C E_{3^{-}}$ mechanism. (E) A combination of (A) and (B) mechanisms, a $C_{3}{ }^{\text {fast }} E_{1}{ }^{\text {irrev }} C E_{3}$-mechanism. (B), (D) and (F) represent the variation of the peak current function, $\Psi_{p}$, with $v(\sigma>10)$ for the $C_{S}^{\text {fast }} E_{4}{ }^{\text {irrev }}-, E_{1}{ }^{\text {irrev }} C E_{3^{-}}$, and $C_{S}^{\text {fast }} E_{1}{ }^{\text {irrev }} C E_{3}$-mechanisms, respectively. Theoretical curves $\left(\Psi_{p}{ }^{0}\right)$ for simple reversible and irreversible, $\alpha=0.5$, (dashed) charge transfers with $n$ $=1,2$ and 4, in stationary electrodes are also given. In simulations, $D_{\text {reactant }}=D_{\mathrm{O}_{2}}=$ $1.93 \times 10^{-5} \mathrm{~cm}^{2} \mathrm{~s}$ and $D_{\text {products }}=1.0 \times 10^{-5} \mathrm{~cm}^{2} \mathrm{~s}$.

Similar curves for this mechanism, but with a first fast charge transfer, are given in Figures $\mathrm{S} 4 \mathrm{~A}$ and $\mathrm{S} 4 \mathrm{~B}$. In these simulations, system parameters, $D_{z}, C^{0}$ and $\mathrm{v}$, were chosen to be equal to analogous parameters for dissolved oxygen in $0.1 \mathrm{M} \mathrm{HClO}_{4}$, given in previous paragraphs, $D_{\mathrm{O}_{2}}$ and $\mathrm{C}^{0} \mathrm{O}_{2}$, and the concentration of surface active sites was assumed constant. A value of $1.0 \times 10^{-5} \mathrm{~cm}^{2} \mathrm{~s}$ was selected for both $D_{A}$ and $D_{B}$, and its magnitude was chosen to be an intermediate value between $\mathrm{D}_{\mathrm{O}_{2}}$ and the diffusion coefficient for $\mathrm{H}_{2} \mathrm{O}_{2}$ in $0.1 \mathrm{M} \mathrm{HClO}_{4}$, reported to be $0.87 \times 10^{-5} \mathrm{~cm}^{2} \mathrm{~s}$ [79]. A decrease in diffusion coefficients is expected between molecules of similar mass but different magnitude of the charge and/or number of hydrogen bonds with the solvent [80].

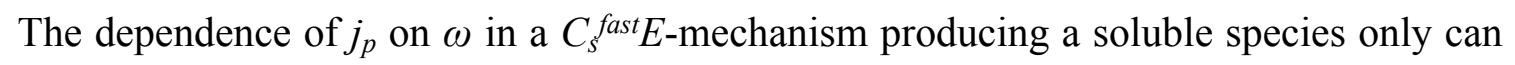
be evidenced by comparing LSVs under transient conditions at different scan rates at stationary electrodes and RDEs. Only in this way two different $\delta_{\text {diff }}$ could be established under certain working conditions: one determined by $\omega, \delta_{\omega}$, and one dictated by diffusion of the electroactive species. If the initial surface chemical reaction is fast enough to originate a $\delta_{\text {diff }}$ larger than $\delta_{\omega}$ at an accessible rotation rate, then currents in nonstationary LSVs at that rotation rate are going to be affected by the magnitude of $\omega$, and different from the ones at stationary electrodes, as it is seen in Figs. 4A and 4B. In contrast, when convection predominates over diffusion, as in steady-state RDEs measurements, $\delta_{\text {diff }}=\delta_{\omega}$ for both species and typical sigmoidal, S-shaped curves of convective systems are recorded.

For other reaction schemes, such as simple multi-electron transfers, a chemical reaction following multi-electron transfers (an EC-mechanism), or EC-mechanisms followed by a first- or second-order disproportionation (a DISP-mechanism), changes in $j_{p}$ with $v$ are not affected by $\omega$, and $j_{p}$ at stationary electrodes and RDEs under non-steady state conditions superimpose, as confirmed by digital simulations $[17,60-64,67,69]$. Contrary to the $C_{s}{ }^{\text {fast }} E-$ mechanism, this result holds true even in those cases when different diffusion coefficients 
for reagents and products are considered. As an example, Figs. 4C and 4D illustrate simulated changes in the normalized $j_{p}$ and the peak current function, $\Psi_{p} E_{I} C E_{3}$, as a function of $\sqrt{\frac{n_{a} F v}{R T}}$ and $v$ for a first-order chemical reaction between two charge transfers with a first slow charge transfer, and $E_{1}{ }^{\circ}<E_{2}^{\circ}$ (an $E_{1}{ }^{i r r e v} C E_{3}$-mechanism), respectively. Similar curves for this mechanism but with a first fast charge transfer are given in Figs. S4C and S4D. Simulations conditions were similar to the ones employed for the $C_{S}^{\text {fast }} E$-mechanism just described above.

\subsection{A chemical step after the first charge transfer}

A clear difference concerning curves in Fig. 2A and Fig. 4A is the leveling in $j_{p}{ }^{O R R}$ 's at increasing scan rates in Fig. $2 \mathrm{~A}$, compared to the continuous increase in $j_{p}$ with $\sqrt{ }_{v}$ in Figs. 4A, as expected from Eqn. (7). Besides, while $\Psi_{p}^{O R R}$ 's at RDEs in Fig. $2 \mathrm{~B}$ practically superimpose for $\omega \geq 1000 \mathrm{rpm}$, simulated $\Psi_{p}{ }^{C s f a s t E}$ curves in Fig. 4B shift to higher values of $v$ by increasing $\omega$. These differences among experimental and calculated curves suggest the presence of another chemical reaction in the ORR mechanism, one between two charge transfers, not accounted by simulations in Figs. 4A and 4B. Kinetic effects due to an initial chemical reaction before the first charge transfer comprise the dependence of $j_{p}$ on $\omega$, if the formed species in the chemical reaction is soluble as explained above, and a decrease in $j_{p}$ at scan rates faster than the time scale of the chemical reaction, instead of approaching a constant value as in Fig. 2A.

As it can be appreciated in Figs. 4C and 4D, a leveling on $j_{p}$ 's values at increasing $v$ is a characteristic feature of an ECE- mechanism, Eqns. (12c) to (12e). In this case, the product of the chemical step, $C$ in Eqn. (12d), is electrochemically more reactive than the species in the initial charge transfer, $A$ in Eqn. (12c), $E_{C / D}{ }^{0}>>E_{A / B}{ }^{0}[26-30,33,49-51,53-54]$. Otherwise, if $E_{C / D}{ }^{0}<<E_{A / B}{ }^{0}$, a second reduction wave, if $C$ is a soluble species, or a peak before or after the main reduction peak, if $C$ is an adsorbed state, should appear in the CV [26,33,50]. As this is not the case in LSVs in Fig. 1, the sigmoidal decrease in $\Psi_{p}{ }^{O R R}$ as $v$ increases in Fig. 2B indicates that an ECE-mechanism, Eqns. (12c) to (12e), follows the initial surface chemical reaction, Eqns. (12a) and (12b).

$$
\begin{gathered}
B \rightleftarrows C \\
C+n_{2} e^{-} \rightleftarrows D
\end{gathered}
$$

Now, because $\Psi_{p}^{O R R}$ 's in Fig $2 \mathrm{~B}$ continuously decrease with $v$ to the point where $\Psi_{p} O R R$ is smaller than $\Psi_{p}^{0}$ for a $1 \mathrm{e}^{-}$charge transfer, only one electron is passed in the first charge transfer, Eqn. (12c), before the chemical reaction, Eqn. (12d), while the other remaining three 
electrons should occur in the second charge transfer process, Eqn. (12e). The existence of an $E_{1} C E_{3}$-mechanism implies a gradual transition in the LSV from a $\Psi_{p}$ characteristic of a combined response of the two electrochemical steps, $n_{1}+n_{2}$ in Eqns. (12c) and (12e), to one $\Psi_{p}$ corresponding to the first electron transfer, $n_{l}$ in Eqn. (12c), at increasing $v$. This transition takes place because at fast $v^{\prime} \mathrm{s}$ the experiment is finished before Eqn. (12d) could occur at full extent and so, Eqn. (12e) cannot make a significant contribution to the total current [26$30,33,50,51,53-54]$.

An $E_{1} C E_{3}$-mechanism can be identified only when the time scale of the experiment is comparable to the half-life, $\tau_{1 / 2}$, of the chemical reaction between the two charge transfer, Eqn. (12d) $[27-30,33,49-51,53-54]$. Then, data in Fig. 2B can be used to get a first approximation of the value of $\tau_{1 / 2}$ during the ORR, by using the sweep rate at which $\Psi_{p}{ }^{O R R}$ has risen to half of its maximum value in [81]. If data at $\omega \geq 1000 \mathrm{rpm}$ are employed, when curves become practically independent of $\omega$, the scan rate at which $\Psi_{p} O R R$ reaches the expected value for a transference of two electrons is between 12 to $20 \mathrm{~V} \mathrm{~s}^{-1}$, depending on the degree of reversibility of the first charge transfer. The equivalent time constant for these scan rates is around 1 to $2 \mathrm{~ms}$ [26], and so, $\tau_{1 / 2}$ is $\sim 1$ to $2 \mathrm{~ms}$ for the chemical reaction represented by Eqn. (12d). Nevertheless, within this criterion, it appears that $\tau_{1 / 2}$ would depend on $\omega$ since at lower $\omega$ and stationary electrodes $\Psi_{p}^{O R R}$ curves in Fig. $2 \mathrm{~B}$ are shifted toward slower scan rates.

An species with a $\tau_{1 / 2}$ of $\sim 2 \mathrm{~ms}$ would diffuse an average distance of $\sim 3 \mu \mathrm{m}$ before reacting, calculated as $\sqrt{ }\left(2 D \tau_{1 / 2}\right)$ [26]. This value would be outside the detection capability of a rotating ring disk electrode (RRDE) set up, for which a $\tau_{1 / 2}$ of the order of $10 \mathrm{~ms}$ or larger has been predicted to be required if the existence of an intermediate is going to be demonstrated by the ring after a potential step [82]. Indeed, larger $\tau_{1 / 2}$ times should be experimentally required, considering that digital simulations of RRDEs have evidenced a lack of response in the ring below $7 \mathrm{~ms}$, and calculated typical transit times of $\sim 30 \mathrm{~ms}$ at $1000 \mathrm{rpm}$ for a rather narrow gap $[26,83,84]$. The transit time of a given RRDE set up is defined as the time required for an species to travel the gap from the outside of the disk to the inside edge of the ring $[26,83,84]$.

Instead, the presence of this intermediate could be detected by scanning electrochemical microscopy (SECM) experiments by using the substrate-generation/tip-collection mode. In this case, oxidation currents during the ORR at $\mathrm{Pt}$ (poly) have been already reported at the $\mathrm{Pt}$ ultramicroelectrode probe (UME) $[85,86]$. For potential steps from a potential $E_{i}>E_{\text {onset }}$ ORR to a potential in the mass-transport controlled region, oxidation currents are measured right 
after a step but only within the first $0.25 \mathrm{~s}$, and at small distances from the surface, $\sim 4$ to 12 $\mu \mathrm{m}$ [85]. This result was interpreted in terms of $\mathrm{H}_{2} \mathrm{O}_{2}$ production during the ORR, but it can also be compatible with the existence of a short-lived intermediate species.

Similarly, experimental conditions under high mass transport coefficients that allow the formation of thin diffusion layers smaller than $3 \mu \mathrm{m}$ could be also useful to detect the participation of this species in the ORR mechanism. This is the case of working, for example, either with microelectrodes with diameters smaller than $5 \mu \mathrm{m}[26,42]$, or with spare arrays of nanoparticles with a particle size small enough to achieve conditions equivalents to $\omega>$ $40000 \mathrm{rpm}$ [87-92]. In agreement, ORR studies at nanostructured Pt electrodes in acid [39], and Pt microelectrodes in neutral and alkaline solutions [93] have independently reported effective electron-transfer numbers lower than 4 and an elevated production of $\mathrm{H}_{2} \mathrm{O}_{2}$ under this conditions.

On the other hand, a $\tau_{1 / 2}$ of $\sim 2 \mathrm{~ms}$ for a first-order chemical reaction would be equivalent to a rate constant of $\sim 350 \mathrm{~s}^{-1}$ [26]. Considering this value, LSVs profiles for an $E_{1} C E_{3^{-}}$ mechanism with $E_{1}{ }^{\circ}<E_{2}{ }^{\circ}$ were calculated. However, from this simulation, it was realized that slower reaction rates are required to represent the decrease in $j_{p}{ }^{O R R}$ 's in Figs. 2A. Figs. 4C and 4D show simulated normalized $j_{p}$ 's and current functions against normalized scan rates for this $E_{1} C E_{3^{-}}$mechanism for a first slow charge transfer and a rate constant rate of $100 \mathrm{~s}^{-1}$ for the first-order chemical reaction between the charge transfers, Eqns. (12d). Analogous curves for a first fast charge transfer are given in Fig. S4C and S4D. From these curves, it is clear that the decrease in $j_{p}{ }^{O R R}$ 's at fast scan rates in Fig. 2 can be qualitatively well described by this mechanism, especially for curves at RDEs with $\omega \geq 1000 \mathrm{rpm}$.

Here it is worth mentioning that the leveling in $j_{p}{ }^{O R R}$ 's in Fig. 2A could be, in principle, also described by a DISP-mechanism in which $C$ in Eqn. (12d) undergoes a disproportionation reaction with $B$ or with itself to partially regenerate the initial reagent, $Z$, as represented by Eqns. (12f) and (12g) [27,30,49,51,90]. If this were the case, similar simulated curves to those ones in Figs. 4C and 4D for an ECE-mechanism would be obtained for a DISP-mechanism if the chemical step is the RDS, a DISPI-mechanism $[27,30,49,51,90]$. Therefore, it would be not possible to differentiate between these two mechanisms from the experimental data in Fig. 1. The possible occurrence of any of these mechanisms, together with the possibility that both mechanisms can simultaneously occur, is commonly referred in the literature as an $E_{1} C E_{3} / D I S P 1$-mechanism, to indicate the 
possibility that the second electron could be provided either by the electrode $\left(E_{1} C E_{3}\right)$ or by a homogeneous electron transfer of $B$, or $C$ in the solution (DISPI).

$$
\begin{aligned}
& B+C \rightleftarrows D+Z \\
& 2 C \rightleftarrows D+Z
\end{aligned}
$$

\subsection{Initial steps in the ORR on Pt surfaces}

When a fast chemical reaction takes place before a charge transfer, the system dynamics at scan rates with an equivalent characteristic time larger than the timescale of the initial chemical reaction becomes the one dictated by the subsequent controlling steps. Accordingly, first steps in the ORR mechanism on Pt surfaces would follow a $C_{s}^{\text {fast }} E_{l} C E_{3}$ scheme, Eqns. (12a) to (12e), with $n_{1}=1$ in Eqn. (12c), and $n_{2}=3$ in Eqn. (12e). Figs. 4E and 4F show simulated changes in the normalized $j_{p}$ and the peak current function, $\Psi_{p}{ }^{C s f a s t E_{1} C E_{3}}$, as a function of $\sqrt{\frac{n_{a} F v}{R T}}$ and $v$ for a $C_{s}^{\text {fast }} E_{l}{ }^{\text {irrev }} C E_{3}$-mechanism with a first slow charge transfer, calculated by combining parameters employed in simulations in Figs. 4A to 4D. Similar curves for this mechanism but with a fast first charge transfer are given in Figs S4E and S4F.

As it can be appreciated, curves in Figs. 4E and 4F and S4E and S4F qualitatively capture main features of experimental data given in Fig. 2, i.e. the dependence of $j_{p}{ }^{O R R}$ 's with $\omega$ and its levelling as $v$ increases. This is especially true if it is considered that the first electron transfer is slow, as in simulations in Fig. $4 \mathrm{~F}$ where $\Psi_{p}{ }^{C s f a s t E_{l} C E_{3}}$ 's at RDEs approach a value close to 2 at fast scan rates, as experimentally measured.

Nevertheless, some important characteristics cannot be still described by this mechanism. The most noticeable difference being the faster experimental decrease in $j_{p}{ }^{O R R}$, $s$ at increasing $v$ at stationary and rotation electrodes at slow $\omega(70 \mathrm{rpm})$ seen in Fig. 2, relative to simulated curves in Figs. 4E and 4F. In addition, as it can be seen in Figure S5, simulated curves of the $C_{s}{ }^{\text {fast }} E_{l}{ }^{\text {irrev }} C E_{3}$-mechanism at steady state have smaller $j_{\text {lim }}$ 's than those expected for a fourelectron transfer, predicted by the Levich equation, Eqn. (10), and as experimentally measured in Fig. S3, and the magnitude of this difference between simulated and experimental $j_{\text {lim }}$ 's increases at faster rotation rates.

A faster decay in currents under transient conditions in an $E_{1} C E_{3}$ scheme can only be achieved by assuming a smaller value than $100 \mathrm{~s}^{-1}$ for the rate constant of the chemical reaction between the charge transfers, Eqn. $(12 \mathrm{~d})$. However, in this case, even lower $j_{\text {lim }}$ 's at steady state than those ones in Fig. S5 would be reached. Contrarily, $j_{\text {lim }}$ 's comparable to the experimental ones can only be obtained in an $E_{l} C E_{3}$ scheme by employing a larger value 
than $100 \mathrm{~s}^{-1}$ for Eqn. (12d). Therefore, there is an apparent dichotomy between experiments and simulated curves at transient and steady-state conditions. While a lower rate constant for Eqn. (12d) is required for obtaining a faster decay in currents at increasing $v$ in simulated curves at transient conditions, a faster rate constant would be needed for simulated $j_{\text {lim }}$ at RDEs to be similar to the ones experimentally measured at steady state conditions.

This fact implies that there is still an important piece missing from the ORR mechanism in the picture described above. This contradictory situation can be brought together by considering the existence of competing, parallel reaction(s) besides the main $C_{S}^{\text {fast }} E_{1} C E_{3^{-}}$ mechanism. In this regard, it has been reported that the occurrence of chain processes in the diffusion layer because of the presence of additional parallel competing reactions inside a main ECE-mechanism may cause a faster current decay than the one found in a simple ECEscheme without this complication. This is the case, for example, of electrochemically induced chemical reactions [94]. This dynamics may appear when the product's redox couple has a standard potential positive to that of the reactant's redox couple, $E_{\text {Product }}{ }^{0}>E_{\text {Reactant }}{ }^{0}$, and it should be considered to occur always that a crossing between the positive- and negativegoing scans is measured in LSVs [94].

In the case of the ORR at Pt surfaces, the condition $E_{\text {Product }}{ }^{0}>E_{\text {Reactant }}{ }^{0}$ can be fulfilled if either $\mathrm{HO}_{2}{ }^{*}$ radicals or $\mathrm{H}_{2} \mathrm{O}_{2}$ were intermediate species in the reaction, and it could also explain the well-known crossing between the positive- and negative-going scans close to $E_{\text {onset }}$ ORR during the reaction, evidenced in Fig. S3 $[9,10,18]$, commonly attributed to an inhibiting role of O-containing species. If this were the case, the rate constant of $\sim 350 \mathrm{~s}^{-1}$ calculated from data in Fig. 2 would not correspond to the one of Eqn. (12d) that should have a higher order of magnitude, but it would represent the time constant of the global scheme, including the effect of the competing reaction(s).

Inside this view, by including the existence of parallel reactions in simulations a faster rate constant than $100 \mathrm{~s}^{-1}$ for Eqn. (12d) can be employed and it would give rise to both $j_{\text {lim }}$ 's comparable to the experimental ones and a faster decay in currents at increasing $v$ than the one in Figs. 4C to 4F. Nevertheless, at this point the exact nature of these competing reactions it is unknown, and more work is still required to validate or reject this analysis. Here, it could be proposed as possible parallel competing reactions the disproportionation of $\mathrm{HO}_{2}{ }^{*}$ radicals, Eqns. (4) and (5), and/or the oxidation of $\mathrm{H}_{2} \mathrm{O}_{2}$, Eqn. (-2), as previously suggested from a preliminary analysis [17]. 
Additional information regarding a reaction mechanism can be gained by analyzing the rate at which either the peak potential, $E_{p}$, or the whole wave shifts along the potential axis as $v$ and $\omega$ are changed [26-32,49,51-53,90,91], as in Figure 5. In this figure, because some voltammograms do not exhibit a peak but S- shaped curves, and in order to minimize the possible influence of the uncompensated resistance between the reference and the working electrodes, the half-peak, $E_{p / 2}$, and half-wave $E_{\omega / 2}$ were used instead of $E_{p}$. As it has been validated before, the analysis of $E_{p / 2}$ and $E_{\omega / 2}$ gives exactly the same information than the analysis of $E_{p}$ 's $[26,32]$.

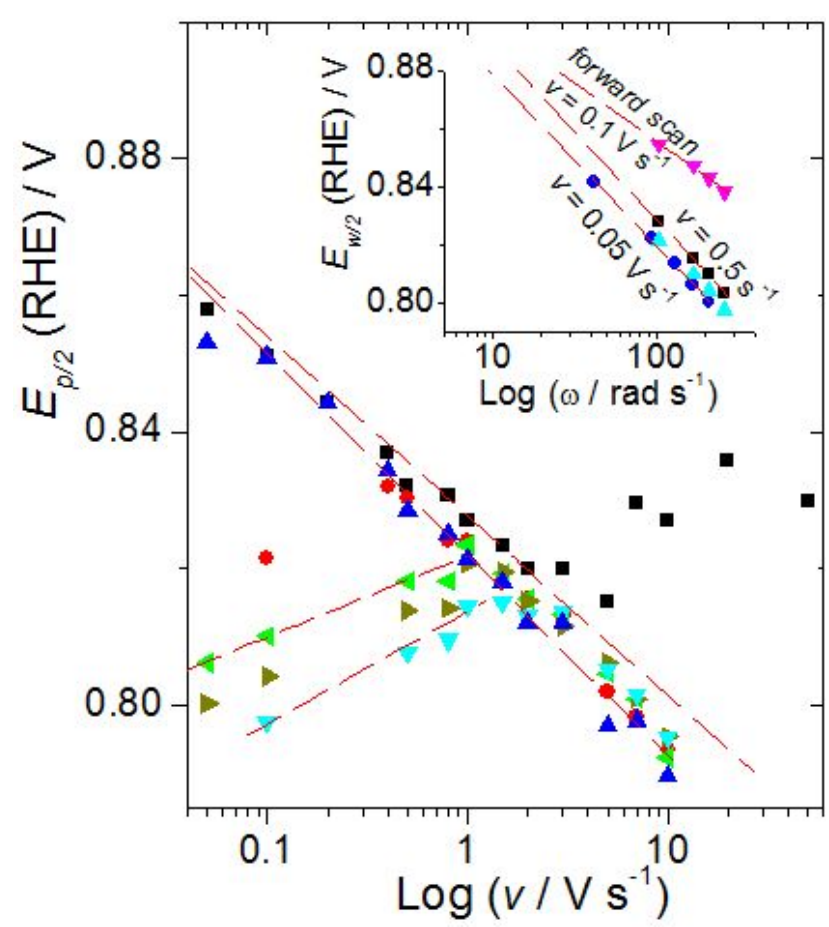

Figure 5: Variation of the half-peak, or half-wave, potential for the oxygen reduction in $\mathrm{O}_{2}$ saturated solutions on $\mathrm{Pt}($ poly) as a function of the scan rate at different $\omega$ 's (main figure), same symbols as in Figs. 2 and 4, and of the rotation rate at different v's (inset). $0.05(\bullet)$; $0.1(\Delta) ; 0.5 \mathrm{~V} \mathrm{~s}^{-1}(\mathbf{\square})$ for data in negative-going LSVs, and $0.1 \mathrm{~V} \mathrm{~s}^{-1}(\nabla)$ for data in positivegoing LSVs.

From Fig. 5, it is found that $E_{p / 2} O R R$ varies linearly by $\sim-26.3$ to $-29.4 \mathrm{mV}$ in the negative direction of the scan for a tenfold increase in $\log v$, equivalent to a Tafel slope twice of this change, i.e. $\sim 52.6$ to $-58.8 \mathrm{mV}$ [26-32,49,51-53,90,91]. This result is compatible with a main $E C E$-mechanism in which the chemical reaction following the first electron transfer, Eqn. (12d), is the RDS [27-31,33,51-54]. In addition, considering that ORR studies at different 
concentrations of $\mathrm{O}_{2}$ at $\mathrm{Pt}\left(\right.$ poly) have suggested a first order reaction relative to $\mathrm{C}^{0} \mathrm{O}_{2}$ as $\mathrm{RDS}$, then a first-order chemical reaction would be the RDS [35,45]. In contrast, $E_{\omega / 2} O R R$ changes by $\sim-59.6 \mathrm{mV}$ for a tenfold increase in $\omega$, equivalent to a Tafel slope of $\sim-119.2 \mathrm{mV}$, as it is seen in inset to Fig. 5, [26], compatible with a first charge transfer as RDS, Eqn. (12c).

The difference in calculated Tafel slopes from changes in $E_{p / 2} O R R$ with $\log v$ and $E_{\omega / 2} O R R$ with $\omega$ is similar to the change in Tafel slopes at $\mathrm{Pt}($ poly) reported by analyzing steady-state polarization curves at low and high current densities, as in Fig. S3A. In this case, the change in Tafel slopes is typically explained as a consequence of a change from Temkin to Langmuir adsorption conditions of ORR intermediates when decreasing the potential, because of desorption of O-containing species adsorbed on the Pt surface [9,10,14-16,34-36,45]. However, in light of result discussed above, this result could be equally interpreted as consequence of a change in the RDS from the chemical reaction between the charge transfer, Eqn. (12d), to the first charge transfer step, Eqn. (12c), when going from high to low potentials [26-33,51-54], considering the existence of competing oxidation reactions at high potentials.

Similar curves to those in Fig. 5 but from simulated LSVs for the $C_{S}^{\text {fast }} E_{1} C E_{3}$-mechanism are given in Figure S6. Here, data for both first fast and slow charge transfers are given, Figs. $\mathrm{S} 6 \mathrm{~A}$ and $\mathrm{S} 6 \mathrm{~B}$, respectively. In these cases, both $E_{p / 2} O R R$ vs. $v$ and $E_{\omega / 2} O R R$ vs. $\omega$ present the same dependence, being $\sim 29.5$ to $34.3 \mathrm{mV}$ and 69.5 to $71 \mathrm{~V}$ for the first fast and slow charge transfers, respectively. Therefore, the change in slopes in Fig. 5 during the ORR cannot be explained by the main $C_{S}^{\text {fast }} E_{1} C E_{3}$-mechanism, and it could be either a consequence of Temkin adsorption conditions for ORR intermediate, or because of the presence of competing reaction(s) in the mechanism, as discussed above. In this sense, Tafel slopes close to $60 \mathrm{mV}$ have been reported for both the oxidation and reduction of $\mathrm{H}_{2} \mathrm{O}_{2}$ on Pt surfaces [75], and it may indicate this reaction as a possible competing step during the ORR, as suggested in a previous work [17].

On the other hand, notice that in both Figs. 5 and S6 there is an inversion in the tendency of how $E_{\omega / 2} O R R$, or $E_{p / 2} O R R$, changes with $v$ at RDEs. Initially $E_{\omega / 2} O R R$ from S-shaped curves moves toward more positive potentials as $v$ increases but later, once a threshold value of $v$ is reached, the tendency reverses, and $E_{p / 2} O R R$ from peak-shaped curves shifts now to less positive potentials with a further increase in $v$. This inversion in the tendency of how $E_{\omega / 2} O R R$, or $E_{p / 2} O R R$, changes with $v$ is a consequence of the change in the mass-transport controlling mode, as suggested before from digital simulations of simple reversible and non-reversible 
charge transfer at RDEs [67]. Initially, the system is at steady-state, and it is controlled by the convection of species toward the surface but later, as $v$ increases, it shifts to a diffusional control at transient conditions. Only in this later case, changes in $E_{p / 2} O R R$ are dictated by the reaction mechanism of the system under study [26-33,51-54].

Experimental ORR studies at RDEs have also reported a positive change of $E_{\omega / 2}{ }^{O R R}$ with $v$, but, contrarily, results in those works were interpreted as consequence of an inhibiting role on the reaction of the amount of oxide formed on Pt surfaces [70,71], which also decreases upon increasing $v[56,68,70,71]$. However, digital simulations in Figs. 5 and S5 confirm that the positive change of $E_{\omega / 2} O R R$ with $v$ before the appearance of the peak, indicative of diffusional control $[61,67,69]$, is more likely caused by a convective process under nonsteady state than because of an inhibiting role of O-containing species, a process not included on those simulations.

\subsection{A proposed mechanism for the ORR on Pt surfaces}

Despite insightful results discussed in the past section, a complete quantitative treatment of the electrochemical data to extract reliable kinetic parameters for the ORR on platinum surfaces cannot be realized yet, since some aspects are not fully understood so far. Nevertheless, results allowed to identify the CECE structure of the first steps in the ORR mechanism and this enables to propose a possible set of initial reactions that fulfill the qualitative features exposed along the analysis.

Classically, investigations about the mechanism of the ORR have considered two main possible reaction schemes: the "dissociative" and the "associative" mechanisms. In the first case, the rupture of the $\mathrm{O}-\mathrm{O}$ bond either precedes the reduction and protonation, or takes place in the first electron transfer, as in Eqn. (13) [11,12,74,95-97]. In the second case, one (or two) reduction step(s) precedes the bond breaking, as in Eqns. (14) or (15) [9,10,14-16,34$36,96]$.

$$
\begin{gathered}
\mathrm{PtO}_{2, a d s}+\mathrm{PtH}_{2} \mathrm{O}_{a d s}+\mathrm{H}^{+}+e^{-} \rightleftarrows \mathrm{PtO}_{a d s}+\mathrm{PtOH}_{a d s}+\mathrm{H}_{2} \mathrm{O} \\
\mathrm{PtO}_{2, a d s}+\mathrm{H}^{+}+e^{-} \rightleftarrows \mathrm{PtHO} \mathrm{O}_{2, a d s}^{*} \\
\mathrm{O}_{2}+2 \mathrm{PtH}_{2} \mathrm{O}_{\mathrm{ads}} \rightleftarrows \mathrm{PtOH}_{\text {ads }}+\mathrm{PtHO}_{2, a d s}^{*}+\mathrm{H}_{2} \mathrm{O}
\end{gathered}
$$

From results described above, the O-O bond dissociative mechanism should be discarded as an operative path on $\mathrm{Pt}$ in acid at high potentials since neither $\mathrm{O}_{\text {ads }}$ nor $\mathrm{OH}_{\text {ads }}$ could fulfill the requirement of the formation of a soluble species with a $\tau_{1 / 2} \sim 2 \mathrm{~ms}$, in agreement with early studies [9,10,14-16,34-36]. Hence, only an associative mechanism could explain 
experimental data and the rupture of the O-O bond should take place either in the second chemical reaction after the first electron transfer, Eqn. (12d), or after this step, Eqn. (12e). In this framework, the first step in the mechanism should be a chemical reaction between $\mathrm{O}_{2}$ and the surface. A step that should not consist of a direct displacement of $\mathrm{H}_{2} \mathrm{O}_{\text {ads }}$ by $\mathrm{O}_{2}$, but should comprise the interaction of $\mathrm{O}_{2}$ with the $\mathrm{O}_{\text {ads }} / \mathrm{OH}_{\mathrm{ads}} / \mathrm{H}_{2} \mathrm{O}_{\text {ads }}$ network on the Pt surface [18], formed through the reduction/oxidation surface process of Pt, Eqns. (-16) or (-17), as suggested by theoretical calculations [97].

$$
\begin{array}{rr}
\mathrm{PtOH}_{a d s}+H^{+}+e^{-} \rightleftarrows \mathrm{PtH}_{2} \mathrm{O}_{a d s} & (16,-16) \\
\mathrm{PtO}_{a d s}+H^{+}+e^{-} \rightleftarrows \mathrm{PtOH}_{a d s} & (17,-17)
\end{array}
$$

Then, it is proposed that the formation of adsorbed superoxide, $\mathrm{O}_{2, \text { ads }}{ }^{-}$, without a direct charge transfer, Eqn. (18), is the initial chemical reaction, coupled with the immediate reduction of the formed $\mathrm{OH}_{\mathrm{ads}}$, Eqn. (17). The influence of the surface on the $p K a$ of adsorbed species would stabilize $\mathrm{O}_{2}^{-}$,ads on the surface $[98,99]$, despite a $p K a \sim 4.8$ for this species in solution, and $\mathrm{O}_{2}$ reduction would be promoted by adsorbed $\mathrm{O}$-containing species, probably $\mathrm{OH}_{\mathrm{ads}}$.

$$
\mathrm{O}_{2}+\mathrm{PtOH}_{\text {ads }} / \mathrm{H}_{2} \mathrm{O}_{\text {ads }} \rightleftarrows \mathrm{PtOH} \text { ads } / \mathrm{OH}_{\text {ads }}-\mathrm{O}_{2, \mathrm{ads}}^{-}+\mathrm{H}^{+}
$$

The formation of the superoxide ion would be followed by its protonation and this step would be the second chemical reaction in the mechanism, Eqn. (12d), which can occur thought either a heterogeneous or a homogeneous reaction. Considering data in Table S1, the homogeneous protonation is expected to be faster than the heterogeneous one, which agrees with theoretical calculations that have suggested that $\mathrm{O}_{2}$ does not directly accept protons during reduction steps [97]. Thus, $\mathrm{O}_{2}^{-}$ads would desorb and go to the solution, where it would be immediately protonated to $\mathrm{HO}_{2}{ }^{*}$, Eqn. (19), and this step would be the RDS under diffusion controlled conditions, as discussed above.

$$
\mathrm{O}_{2}^{-}+\mathrm{H}^{+} \rightleftarrows \mathrm{HO}_{2}^{*}
$$

It could be also possible however, that the first chemical step in the mechanism would be the production of $\mathrm{HO}_{2}{ }^{*}$,ads, Eqn. (20), and the concerted reduction of $\mathrm{OH}_{\mathrm{ads}}$ the first electrochemical step, Eqn. (17). Next, the dissociation of $\mathrm{HO}_{2}{ }^{*}$,ads into $\mathrm{O}_{\text {ads }}$ and $\mathrm{OH}_{\mathrm{ads}}$, or two $\mathrm{OH}_{\text {ads }}$, in a chemical reaction, Eqns. (21a) or (21b), would be the second chemical reaction in the mechanism, due to the instability of $\mathrm{HO}_{2}{ }^{*}$,ads on the surface at high potentials $[6,100]$. This step would be the RDS at high but not at low potentials, since $\mathrm{HO}_{2}{ }^{*}$,ads dissociation strongly depends on the number of Pt free sites on the water, or $\mathrm{H}_{2} \mathrm{O}_{\mathrm{ads}} / \mathrm{OH}_{\mathrm{ads}}$, covered surface, relative to the bare electrode [101], explaining the change in Tafel slopes. 
Theoretical calculations have shown that this step would only occur with a small barrier if there is one empty site on the surface, but barrierless if two empty sites are available [101].

$$
\begin{aligned}
& \mathrm{O}_{2}+\mathrm{PtOH}_{\text {ads }} / \mathrm{H}_{2} \mathrm{O}_{\text {ads }} \rightleftarrows \mathrm{PtOH} \mathrm{H}_{\text {ads }} / \mathrm{OH}_{a d s}-\mathrm{HO}_{2, \text { ads }}^{*} \\
& \mathrm{PtHO}_{2, a d s}^{*}+\mathrm{Pt} \rightleftarrows \mathrm{PtO}_{a d s}+\mathrm{PtOH}_{\text {ads }} \\
& \mathrm{PtHO}_{2, a d s}^{*}+2 \mathrm{Pt} \rightleftarrows 3 \mathrm{PtOH} \mathrm{H}_{a d s}+2 \mathrm{H}_{2} \mathrm{O}
\end{aligned}
$$

The nature of the second electrochemical step cannot be precisely known as it is located after the RDS and it would depend on which one of these two proposed mechanisms takes place during the ORR. In the first case, the subsequent reduction of $\mathrm{HO}_{2}{ }^{*}$, Eqn. (6), can be proposed, considering that the reduction potential of this step is expected to be more positive than $E^{0}$ of Eqn. (16), Table S1. Once $\mathrm{H}_{2} \mathrm{O}_{2}$ is formed, next steps in the ORR mechanism should be the cleavage of the O-O, giving rise to two $\mathrm{OH}^{*}$ species [102], and their reduction to $\mathrm{H}_{2} \mathrm{O}$, probably following Eqn. (16), as reported for the reduction of $\mathrm{H}_{2} \mathrm{O}_{2}$ in Pt surfaces [75]. In the second mechanism, next steps would be the reduction of $\mathrm{O}_{\text {ads }}$ and $\mathrm{OH}_{\text {ads }}$ though Eqns. (16) and (17).

Notice that the production of $\mathrm{HO}_{2}{ }^{*}$ as intermediate species in both mechanisms opens the possibility of several parallel subsequent reactions. For example, the second electron could be transferred by the disproportionation of $\mathrm{HO}_{2}{ }^{*}$ giving rise to $\mathrm{H}_{2} \mathrm{O}_{2}$, Eqns. (4) to (5), instead of involving an electrochemical step. But even if this is not the case, these reactions would be always possible competing reactions for the $\mathrm{HO}_{2}{ }^{*}$ radical. Therefore, first steps in the ORR mechanism would be described by a CECE/DISP mechanism, and the participation extent of the $E C E$ - and/or the DISP- schemes cannot be determined from data in Fig. 1, because in that case the chemical reaction between the two charge transfers is the RDS. However, an increase in the contribution of the DISP-scheme is expected to occur at increasing $\mathrm{pH}$ 's [21].

Table 1 summarizes the possible two ORR mechanisms discussed above. Inside any of these mechanisms, the increase in ${E^{0}}_{\mathrm{O}_{2} / \mathrm{O}_{2}-}$ from $\sim-0.33 \mathrm{~V}[80,103,104]$, to potentials close to $E_{\text {onset }}$ ORR on Pt would be explained by the fast protonation that follows the reduction of $\mathrm{O}_{2}$ to $\mathrm{O}_{2}^{-}$, as it has been proposed in the case of the ORR in aprotic solvents [80,95]. Additionally, the interaction of $\mathrm{O}_{2}$ with adsorbed O-containing species on $\mathrm{Pt}$ surfaces that would mediate the $\mathrm{O}_{2}$ reduction, and the reactivity of $\mathrm{Pt}$ toward the reduction of $\mathrm{H}_{2} \mathrm{O}_{2}$ [75] would also contribute to the reactivity of this metal. A simplified scheme for the reaction mechanism proposed to take place close to ORR reaction onset at Pt surfaces, is given in Figure 6. 
Table 1: Summary of the ORR mechanisms on Pt surfaces discussed in the text

\begin{tabular}{|c|c|c|}
\hline Mechanism & General representation & Possible physical interpretation \\
\hline$C$ & $\begin{array}{c}Z+M+F \stackrel{K}{\Leftrightarrow} M-A_{a d s}+B \\
M-A_{a d s} \stackrel{K}{\Leftrightarrow} M+A\end{array}$ & $\begin{array}{c}\mathrm{O}_{2}+\mathrm{PtOH}_{\text {ads }} / \mathrm{H}_{2} \mathrm{O}_{\text {ads }} \rightleftarrows \mathrm{PtOH}_{\text {ads }} / \mathrm{H}_{2} \mathrm{O}_{a d s}-\mathrm{O}_{2, a d s} \\
\mathrm{PtOH}_{\text {ads }} / \mathrm{H}_{2} \mathrm{O}_{\text {ads }}-\mathrm{O}_{2, a d s} \rightleftarrows \mathrm{PtOH} \text { ads } / \mathrm{OH}_{\text {ads }}-\mathrm{O}_{2, a d s}^{-}+\mathrm{H}^{+} \\
\mathrm{PtOH}_{\text {ads }} / \mathrm{OH}_{\text {ads }}-\mathrm{O}_{2, a d s}^{-} \rightleftarrows \mathrm{PtOH} \mathrm{H}_{a d s} / \mathrm{OH}_{a d s}+\mathrm{O}_{2}^{-}+\mathrm{H}^{+}\end{array}$ \\
\hline$E_{1}$ & $B+1 e^{-}+H^{+} \rightleftarrows F$ & $\mathrm{PtOH}_{a d s} / \mathrm{OH}_{a d s}+\mathrm{H}^{+}+1 e^{-} \rightleftarrows P t O H_{a d s} / \mathrm{H}_{2} \mathrm{O}_{a d s}$ \\
\hline$C$ & $B \rightleftarrows C$ & $\mathrm{O}_{2}^{-}+\mathrm{H}^{+} \rightleftarrows \mathrm{HO}_{2}^{*}$ \\
\hline$x E_{1}$ & $C+1 e^{-}+H^{+} \rightleftarrows D$ & $\mathrm{HO}_{2}^{*}+\mathrm{H}^{+}+1 e^{-} \rightleftarrows \mathrm{H}_{2} \mathrm{O}_{2}$ \\
\hline$(1-x) D I S P$ & $\begin{array}{c}B+C+H^{+} \rightleftarrows Z+D \text { ou } \\
2 C \rightleftarrows Z+D\end{array}$ & $\begin{array}{c}2 \mathrm{HO}_{2}^{*} \rightleftarrows \mathrm{H}_{2} \mathrm{O}_{2}+\mathrm{O}_{2} \\
\mathrm{O}_{2}^{-}+\mathrm{HO}_{2}^{*} \rightleftarrows \mathrm{HO}_{2}^{-}+\mathrm{O}_{2} \\
\mathrm{HO}_{2}^{-}+\mathrm{H}^{+} \rightleftarrows \mathrm{H}_{2} \mathrm{O}_{2} \\
\end{array}$ \\
\hline$C$ & $D \rightleftarrows 2 B$ & $\mathrm{H}_{2} \mathrm{O}_{2} \rightleftarrows 2 \mathrm{OH}^{*}$ \\
\hline$E_{2}$ & $B+1 e^{-}+H^{+} \rightleftarrows F$ & $\mathrm{PtOH}_{a d s}+\mathrm{H}^{+}+1 e^{-} \rightleftarrows \mathrm{PtH}_{2} \mathrm{O}_{a d s}$ \\
\hline Mechanism 1 & $Z+4 e^{-}+4 H^{+} \rightleftarrows 2 F$ & $\mathrm{O}_{2}+4 e^{-}+4 \mathrm{H}^{+} \rightleftarrows 2 \mathrm{H}_{2} \mathrm{O}$ \\
\hline$C$ & $\begin{array}{c}Z+M+F \stackrel{K}{\Leftrightarrow} M-C_{a d s}+B \\
M-C_{a d s} \stackrel{K}{\Leftrightarrow} M+C \\
\end{array}$ & $\begin{array}{c}\mathrm{O}_{2}+\mathrm{PtOH} \mathrm{H}_{\text {ads }} / \mathrm{H}_{2} \mathrm{O}_{\text {ads }} \rightleftarrows \mathrm{PtOH} \mathrm{H}_{\text {ads }} / \mathrm{H}_{2} \mathrm{O}_{\text {ads }}-\mathrm{O}_{2, a d s} \\
\mathrm{PtOH}_{\text {ads }} / \mathrm{H}_{2} \mathrm{O}_{\text {ads }}-\mathrm{O}_{2, a d s} \rightleftarrows P t O \mathrm{H}_{\text {ads }} / \mathrm{OH}_{\text {ads }}-\mathrm{HO}_{2, \text { ads }}^{*} \\
\text { PtOH }_{\text {ads }} / \mathrm{OH}_{\text {ads }}-\mathrm{HO}_{2, a d s}^{*} \rightleftarrows \mathrm{PtOH}_{\text {ads }} / \mathrm{OH}_{\text {ads }}+\mathrm{HO}_{2}^{*}\end{array}$ \\
\hline$E_{1}$ & $B+1 e^{-}+H^{+} \rightleftarrows F$ & $\mathrm{PtOH}_{\text {ads }} / \mathrm{OH}_{\text {ads }}+\mathrm{H}^{+}+1 e^{-} \rightleftarrows \mathrm{PtOH}_{\text {ads }} / \mathrm{H}_{2} \mathrm{O}_{\text {ads }}$ \\
\hline$x C$ & $\begin{array}{c}C \rightleftarrows E+B \text { ou } \\
C+F \rightleftarrows 3 B\end{array}$ & $\begin{array}{c}\mathrm{PtHO}_{2, a d s}^{*}+\mathrm{Pt} \rightleftarrows P t \mathrm{O}_{a d s}+\mathrm{PtOH} \mathrm{H}_{a d s} \\
\mathrm{PtHO} \mathrm{O}_{2, a d s}^{*}+\mathrm{PtH}_{2} \mathrm{O}_{a d s}+\mathrm{Pt} \rightleftarrows 3 \mathrm{PtOH} \text { ads }\end{array}$ \\
\hline$(1-x) D I S P$ & $2 C \rightleftarrows Z+D$ & $2 \mathrm{HO}_{2}^{*} \rightleftarrows \mathrm{H}_{2} \mathrm{O}_{2}+\mathrm{O}_{2}$ \\
\hline$\left(\frac{1-x}{2}\right) C$ & $D \rightleftarrows 2 B$ & $\mathrm{H}_{2} \mathrm{O}_{2} \rightleftarrows 2 \mathrm{OH}^{*}$ \\
\hline$E_{3}$ & $\begin{array}{l}E+1 e^{-}+H^{+} \rightleftarrows B \\
B+1 e^{-}+H^{+} \rightleftarrows F\end{array}$ & $\begin{array}{c}\mathrm{PtO}_{a d s}+H^{+}+1 e^{-} \rightleftarrows P t O H_{a d s} \\
\text { PtOH }_{a d s} / \mathrm{OH}_{a d s}+H^{+}+1 e^{-} \rightleftarrows P t O H_{a d s} / H_{2} O_{a d s}\end{array}$ \\
\hline Mechanism 2 & $Z+4 e^{-}+4 H^{+} \rightleftarrows 2 F$ & $\mathrm{O}_{2}+4 e^{-}+4 \mathrm{H}^{+} \rightleftarrows 2 \mathrm{H}_{2} \mathrm{O}$ \\
\hline
\end{tabular}

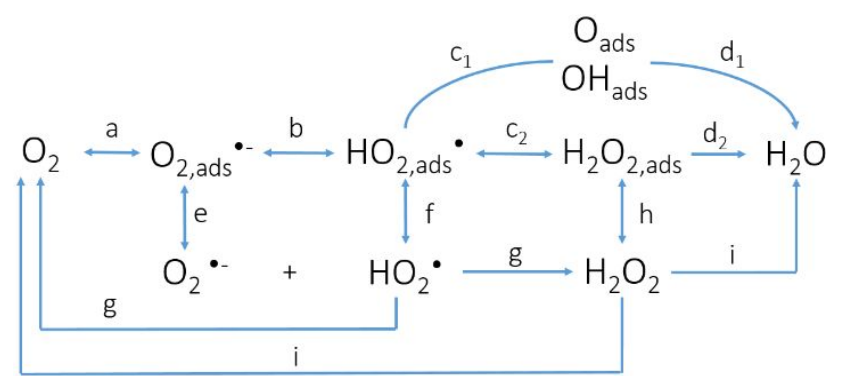

Figure 6. Simplified reaction mechanism proposed to occur close to ORR reaction onset at Pt surfaces.

From this proposed reaction scheme, it can be seen that surface platinum oxides not necessary would be inhibiting species, as commonly accepted [1-5,9,10,45,46,70,71,105]. Instead, the balance between $\mathrm{OH}_{\mathrm{ads}} / \mathrm{O}_{\text {ads }}$ species on the surface may determine the principal reaction occurring at the electrode, either reduction, oxidation, or surface catalyzed decompositions of $\mathrm{HO}_{2}{ }^{*}$, Eqns. (6), (22) to (25), and/or of $\mathrm{H}_{2} \mathrm{O}_{2}$, Eqns. (-2), (3) [75], and (22) 
and (26) [106-110]. This dual dynamics of O-containing species can be the reason for differences in reduction currents between positive- and negative-going scans during the ORR in Fig. S3, and the lack of current at $E_{i}>E_{\text {onset }}$ ORR [17].

$$
\begin{gathered}
\mathrm{PtOH}_{a d s}+\mathrm{H}_{2} \mathrm{O}_{2} \rightleftarrows \mathrm{H}_{2} \mathrm{O}+\mathrm{PtHO}_{2, a d s}^{*} \\
\mathrm{PtOH}_{a d s}+\mathrm{HO}_{2}^{*} \rightleftarrows \mathrm{PtO}_{a d s}+\mathrm{H}_{2} \mathrm{O}_{2} \\
\mathrm{PtOH}_{a d s}+\mathrm{HO}_{2}^{*} \rightleftarrows \mathrm{PtH}_{2} \mathrm{O}_{a d s}+\mathrm{O}_{2} \\
\mathrm{PtO}_{a d s}+\mathrm{HO}_{2}^{*} \rightleftarrows \mathrm{PtOH} \mathrm{H}_{a d s}+\mathrm{O}_{2} \\
\mathrm{PtHO}_{2, a d s}^{*}+\mathrm{H}_{2} \mathrm{O}_{2} \rightleftarrows \mathrm{O}_{2}+\mathrm{H}_{2} \mathrm{O}+\mathrm{PtOH}_{a d s}
\end{gathered}
$$

In this scheme, neither the direct reduction nor disproportionation of $\mathrm{O}_{2}^{-}$in acid are expected to be important steps in the overall reduction, because the protonation of $\mathrm{O}_{2}^{-}$, Eqn. (19), is expected to be under diffusion-limited regime, Table $\mathrm{S} 1$, and both, the $\mathrm{O}_{2}^{-}$ disproportionation, Eqn. (27), and reduction, Eqn. (28), would be comparatively slow $[80,95,103,104]$, Table S1,

$$
\begin{gathered}
2 \mathrm{O}_{2}^{-}+2 \mathrm{H}^{+} \rightleftarrows \mathrm{H}_{2} \mathrm{O}_{2}+\mathrm{O}_{2} \\
\mathrm{O}_{2}^{-}+\mathrm{H}_{2} \mathrm{O}+e^{-} \rightleftarrows \mathrm{HO}_{2}^{-}+\mathrm{OH}^{-}
\end{gathered}
$$

Unfortunately, from the current data, it is not possibly to distinguish between the reaction schemes proposed in Table 1, and possible from others that could be formulated, which one could be the actual ORR mechanism, if indeed there is a single one. It is possible that more than one mechanism is operative and the dominant path changes from one to another depending on the potential, the coverage of O-containing species, among other. More work is still necessary in order to understand the molecular details of the ORR mechanism on Pt surfaces. However, results discussed above certainly give valuable information to accomplish this objective.

Finally, it is important to highlight that the fact that $\mathrm{HO}_{2}{ }^{*}$ radical and $\mathrm{H}_{2} \mathrm{O}_{2}$ would be always produced during the ORR on Pt would seriously influence the stability of Pt-based materials in fuel cell operando conditions, and it should be taken into account in the design of new materials. Accordingly, in order to improve the performance of ORR electrocatalysts, the search for better materials should focus not only in the enhancement of the electrocatalytic activity but, on the other side, in the development of strategies that allow minimizing the effects of $\mathrm{HO}_{2}{ }^{*}$ radicals and $\mathrm{H}_{2} \mathrm{O}_{2}$ in the durability of the cathode catalyst layers.

Besides, the combination of inner- and outer-sphere reactions in the global reaction path, opens the opportunity of designing new catalysts beyond fundamental limits imposed by the ACS Paragon Plus Environment 
apparent scaling relations between probable reaction intermediates, such as $\mathrm{OH}_{\text {ads }}, \mathrm{O}_{\mathrm{ads}}$, and $\mathrm{HO}_{2, \text { ads }}$ adsorbates. In this sense, it would be possible in principle to improve the reduction of $\mathrm{HO}_{2}{ }^{*}$ and $\mathrm{H}_{2} \mathrm{O}_{2}$, or its decomposition to $\mathrm{O}_{2}$ and water by selecting appropriate surrounding conditions, without altering electrocatalytic properties of electrode materials, or by finding a proper balance between surface properties and reacting media. For example, the design of composites that can modify the extension of disproportionation equilibriums, Eqns. (4) and (5), could help to increase the reaction onset, as already reported by the use of ionic liquids in the catalytic layer [7].

\title{
4. Conclusions
}

In this work, the oxygen reduction reaction on platinum surfaces has been characterized at different time scales and by employing diagnostic criteria for common reaction schemes and digital simulations that include chemical processes inside the mechanistic pathway. Results evidence the presence of kinetic complications during the ORR that have been explained by considering the occurrence of an initial Chemical-Electrochemical-ChemicalElectrochemical sequence of steps, coupled to a disproportionation reaction (a CECE/DISP scheme). Under steady-state situations at bulk electrodes, the first charge transfer process is the rate determining step (RDS) but, at diffusion-controlled conditions, the second chemical reaction becomes the RDS at high potentials. In addition, results suggest that dissolved oxygen reacts at potentials higher than the reaction onset, despite the lack of current, and the process occurring at those potentials would control the value of peak currents at lower potentials. Finally, the possible occurrence of some reported reaction steps is analyzed in light of these ideas, and two probable mechanisms are proposed. Although results from this study offer new valuable information, more work is still necessary in order to derive the full ORR mechanism.

\begin{abstract}
Associated content
Supporting information 1: Additional supporting electrochemical characterization, calculated LSV curves for simple reaction schemes by numerical simulation, and estimated thermodynamic and kinetic parameters for the reaction steps discussed through the text (PDF)
\end{abstract}


Supporting information 2: Details regarding the mathematical structure of models discussed in the text, as well as employed boundary conditions and data related to the implementation of the model in COMSOL Multiphysics 5.1 (PDF)

\section{Acknowledgments}

The authors thank the Fundação de Amparo a Pesquisa do Estado de São Paulo, Brazil FAPESP through projects Procs. 2013/16930-7 and 2014/23486-9 (A.G-M. and E.T.), the Spanish MINECO through project CTQ2016-76221-P (FEDER) and GV through PROMETEOII/2014/013 (FEDER) (J.F.), for financial support.

\section{References}

1. K. Kinoshita, Electrochemical Oxygen Technology, Wiley, New York, 1992.

2. Mukerjee, S.; Soriaga, M. P.; McBreen, J. Effect of Preparation Conditions of Pt Alloys on Their Electronic, Structural, and Electrocatalytic Activities for Oxygen Reduction XRD, XAS, and Electrochemical Studies. J. Phys. Chem. 1995, 99, 4577-4589.

3. Teliska, M.; Mukerjee, S.; Ramaker, D. E. Correlation of Water Activation, Surface Properties, and Oxygen Reduction Reactivity of Supported Pt-M/C Bimetallic Electrocatalysts Using XAS. J. Electrochem. Soc. 2005, 152, A2159-A2169.

4. Roques, J.; Anderson, A. B.; Mukerjee, S. Potential Shift for OH(ads) Formation on the Pt Skin on $\mathrm{Pt}_{3} \mathrm{Co}$ (111) Electrodes in Acid. Theory and Experiment. J. Electrochem. Soc. 2005, 152, E193-E199.

5. Stamenkovic, V. R.; Fowler, B.; Mun, B. S.; Wang, G.; Ross, P. N.; Lucas, C. A.; Markovic, N. M. Improved Oxygen Reduction Activity on $\mathrm{Pt}_{3} \mathrm{Ni}(111)$ via Increased Surface Site Availability. Science 2007, 315, 493-497.

6. Nilekar, A. U.; Mavrikakis, M. Improved Oxygen Reduction Reactivity of Platinum Monolayers on Transition Metal Surfaces. Surf. Sci. 2008, 602, L89-L94.

7. Snyder, J.; Fujita, T.; Chen, M.W.; Erlebacher, J. Oxygen Reduction in Nanoporous Metal-Ionic Liquid Composite Electrocatalysts. Nature Mater. 2010, 9, 904-907.

8. Vliet, D. F. van der; Markovic, N. M.; Stamenkovic, V. R. Mesostructured Thin Films as Electrocatalysts with Tunable Composition and Surface Morphology. Nature Mater. 2012, 11, 1051-1058.

9. Damjanovic, A.; Brusic, V. Electrode Kinetics of Oxygen Reduction on Oxide-Free Platinum Electrodes. Electrochim. Acta 1967, 12, 615-628. 
10. Paucirova, M.; Drazic, D. M.; Damjanovic, A. The Effect of Surface Coverage by Adsorbed Oxygen on the Kinetics of Oxygen Reduction at Oxide Free Platinum. Electrochim. Acta 1973, 18, 945-951.

11. Sawyer, D. T.; Interrante, L. V. Electrochemistry of Dissolved Gases: II. Reduction of Oxygen at Platinum, Palladium, Nickel and other Metal Electrodes. J. Electroanal. Chem. 1961, 2, 310-327.

12. Sawyer, D. T.; Day, R. J. Kinetics for Oxygen Reduction at Platinum, Palladium and Silver Electrodes. Electrochim. Acta 1963, 8, 589-594.

13. Llang, C. C.; Juliar. A. L. The Overpotential of Oxygen Reduction at Platinum Electrodes. J. Electrochem. Chem. 1965, 9, 390-394.

14. Damjanovic, A.; Genshaw, M. A.; Bockris, J. O. The Role of Hydrogen Peroxide in the Reduction of Oxygen at Platinum Electrodes. J. Phys. Chem. 1966, 70, 3761-3762.

15. Damjanovic, A.; Genshaw, M. A.; Bockris, J. O. The Role of Hydrogen Peroxide in Oxygen Reduction at Platinum in $\mathrm{H}_{2} \mathrm{SO}_{4}$ Solution. J. Electrochem. Soc. 1967, 114, 466472.

16. Damjanovic, A.; Genshaw, M. A.; Bockris, J. O. The Mechanism of Oxygen Reduction at Platinum in Alkaline Solutions with Special Reference to $\mathrm{H}_{2} \mathrm{O}_{2}$. J. Electrochem. Soc. 1967, 114, 1107-1112.

17. Gómez-Marín, A. M.; Feliu, J. M.; Ticianelli, E. A. Reaction Mechanism for Oxygen Reduction on Platinum: Existence of a Fast Initial Chemical Step and a Soluble Species different from $\mathrm{H}_{2} \mathrm{O}_{2}$. ACS Catal. 2018, 8, 7931-7943.

18. Gómez-Marín, A. M.; Feliu, J. M. New Insights into the Oxygen Reduction Reaction Mechanism on Pt (111): A Detailed Electrochemical Study. ChemSusChem. 2013, 6, 1091-1100.

19. Gómez-Marín, A. M.; Rizo, R.; Feliu, J. M. Oxygen Reduction Reaction at Pt Single Crystals: A Critical Overview. Catal. Sci. Technol. 2014, 4, 1685-1698.

20. Gómez-Marín, A. M.; Feliu, J. M. Role Of Oxygen-Containing Species at Pt(111) on the Oxygen Reduction Reaction in Acid Media. J. Solid State Electrochem. 2015, 19, 28312841.

21. Briega-Martos, V.; Herrero, E.; Feliu J. M. Effect of $\mathrm{pH}$ and Water Structure on the Oxygen Reduction Reaction on Platinum Electrodes. Electrochim. Acta 2017, 241, 497509. 
22. Dong, J.-C.; Zhang, X.-G.; Briega-Martos, V.; Jin, X.; Yang, J.; Chen, S.; Yang, Z.-L.; Wu, D.-Y.; Feliu, J. M.; Williams, C. T.; Tian, Z.-Q.; Li, J.-F. In Situ Raman Spectroscopic Evidence for Oxygen Reduction Reaction Intermediates at Platinum Single-Crystal Surfaces. Nature Energy 2018, DOI: 10.1038/s41560-018-0292-z.

23. Kunimatsu, K.; Yoda, T.; Tryk, D. A.; Uchida, H. Watanabe, M. In Situ ATR-FTIR Study of Oxygen Reduction at the Pt/Nafion Interface. Phys. Chem. Chem. Phys. 2010, 12, 621629.

24. Shao, M.; Liu, P.; Adžić, R. R. Superoxide Anion Is the Intermediate in the Oxygen Reduction Reaction on Platinum Electrodes. J. Am. Chem. Soc. 2006, 128, 7408-7409.

25. Nayak, S.; McPherson, I. J.; Vincent, K. A. Adsorbed Intermediates in Oxygen Reduction on Platinum Nanoparticles Observed by In Situ IR Spectroscopy. Angew. Chem. Int. Ed. 2018, 57, 12855-12858.

26. Bard, A. J.; Faulkner, L. R. Electrochemical Methods: Fundamentals and Applications, 2nd ed.; John Wiley and Sons: New York, 2001.

27. Mastragostino, M.; Savéant, J. -M. Disproportionation and ECE Mechanisms-II. Reduction of the Uranyl Cation in Perchloric Acid. Electrochim. Acta 1968, 13, 751-762.

28. Nadjo, L.; Savéant, J. -M. Electrodimerization VIII. Role of Proton Transfer Reactions in the Mechanism of Electrohydrodimerization Formal Kinetics for Voltammetric Studies (Linear Sweep, Rotating Disc, Polarography). J. Electroanal. Chem. 1973, 44, 327-366.

29. Nadjo, L.; Savéant, J. -M. Linear Sweep Voltammetry: Kinetic Control by Charge Transfer and/or Secondary Chemical Reactions I. Formal Kinetics. J. Electroanal. Chem. 1973, 48, 113-145.

30. Amatore, C.; J.-M. Savéant, ECE and Disproportionation. Part V. Stationary State General Solution Application to Linear Sweep Voltammetry. J. Electroanal. Chem. 1977, $85,27-46$.

31. Savéant, J. -M.; Vianello, E. Potential-Sweep Chronoamperometry Theory of Kinetic Currents in the Case of a First Order Chemical Reaction Preceding the Electron-Transfer Process. Electrochim. Acta 1963, 8, 905-923.

32. Nicholson, R. S.; Shain, I. Theory of Stationary Electrode Polarography Single Scan and Cyclic Methods Applied to Reversible, Irreversible, and Kinetic Systems. Anal. Chem. 1964, 36, 706-723. 
33. Nicholson, R.S.; Shain, I. Experimental Verification of an ECE Mechanism for the Reduction of p-Nitrosophenol, using Stationary Electrode Polarography. Anal. Chem. 1965, 37, 190-195.

34. Damjanovic, A.; Genshaw, A. Dependence of the Kinetics of $\mathrm{O}_{2}$ Dissolution at Pt on the Conditions for Adsorption of Reaction Intermediates. Electrochim. Acta 1970, 15, 12811283.

35. Sepa, D. B.; Vojnovic, M. V.; Damjanovic, A. Reaction Intermediates as a Controlling Factor in the Kinetics and Mechanism of Oxygen Reduction at Platinum Electrodes. Electrochim. Acta 1981, 26, 781-793.

36. Sepa, D. B.; Vojnovic, M. V.; Vracar, L. M.; Damjanovic, A. Apparent Enthalpies of Activation of Electrodic Oxygen Reduction at Platinum in Different Current Density Regions I. Acid Solution. Electrochim. Acta 1986, 31, 91-96.

37. Watanabe, M.; Sei, H.; Stonehart, P. The Influence of Platinum Crystallite Size on the Electroreduction of Oxygen. J. Electroanal. Chem. 1989, 261, 375-387.

38. Inaba, M.; Yamada, H.; Tokunaga, J.; Tasaka, A. Effect of Agglomeration of Pt/C Catalyst on Hydrogen Peroxide Formation. Electrochem. Solid-State Lett. 2004, 7, A474A476.

39. Chen, S.; Kucernak, A. Electrocatalysis under Conditions of High Mass Transport Rate: Oxygen Reduction on Single Submicrometer-Sized Pt Particles Supported on Carbon. $J$. Phys. Chem. B 2004, 108, 3262-3276.

40. Seidel, Y. E.; Schneider, A.; Jusys, Z.; Wickman, B.; Kasemo, B.; Behm, R. J. Mesoscopic Mass Transport Effects in Electrocatalytic Processes. Faraday Discuss. 2008, 140, 167-184.

41. Schneider, A.; Colmenares, L.; Seidel, Y. E.; Jusys, Z.; Wickman, B.; Kasemo, B.; Behm, R.J. Transport Effects in the Oxygen Reduction Reaction on Nanostructured, Planar Glassy Carbon Supported Pt/GC Model Electrodes. Phys. Chem. Chem. Phys. 2008, 10, 1931-1943.

42. Gara, M.; Laborda, E.; Holdway, P.; Crossley, A.; Jones, C.J.V.; Compton, R.G. Oxygen Reduction at Sparse Arrays of Platinum Nanoparticles in Aqueous Acid: Hydrogen Peroxide as a Liberated Two-Electron Intermediate. Phys. Chem. Chem. Phys. 2013, 15, 19487-19495. 
43. Kabbabi, A.; Gloaguen, F.; Andolfatto, F.; Durand, R. Particle Size Effect for Oxygen Reduction and Methanol Oxidation on $\mathrm{Pt} / \mathrm{C}$ inside a Proton Exchange Membrane. $J$. Electroanal. Chem. 1994, 373, 251-254.

44. Antoine, O.; Bultel, Y.; Durand, R. Oxygen Reduction Reaction Kinetics and Mechanism on Platinum Nanoparticles Inside Nafion ${ }^{\circledR}$. J. Electroanal. Chem. 2001, 499, 85-94.

45. Markovic, N. M.; Ross, P. N., Jr. Surface Science Studies of Model Fuel Cell Electrocatalysts. Surf. Sci. Rep. 2002, 45, 117-229.

46. Wang, J. X.; Markovic, N. M.; Adzic, R.R. Kinetic Analysis of Oxygen Reduction on $\operatorname{Pt}(111)$ in Acid Solutions: Intrinsic Kinetic Parameters and Anion Adsorption Effects. J. Phys. Chem. B 2004, 108, 4127-4133.

47. Fischer, P.; Heitbaum, J. Mechanistic Aspects of Cathodic Oxygen Reduction. J. Electroanal. Chem. 1980, 112, 231-238.

48. Scherson, D. A.; Tolmachev, Y. V. Impurity Effects on Oxygen Reduction Electrocatalysis at Platinum Ultramicroelectrodes: A Critical Assessment. Electrochem. Solid-State Lett. 2010, 13, F1-F2.

49. Amatore, C.; Savéant, J.-M. Electrochemical Hydrogenation of Aromatic Hydrocarbons: Discrimination between ECE and Disproportionation Mechanisms by Double Potential Step Chronoamperometry. J. Electroanal. Chem. 1980, 107, 353-364.

50. Nicholson, R. S.; Shain, I. Theory of Stationary Electrode Polarography for a Chemical Reaction Coupled Between Two Charge Transfers. Anal. Chem. 1965, 37, 178-190.

51. Mastragostino, M.; Nadjo, L.; Savéant, J.-M. Disproportionation and ECE MechanismsI. Theoretical Analysis. Relationships for Linear Sweep Voltammetry. Electrochim. Acta 1968, 13, 721-749.

52. Andrieux, C. P.; Nadjo, L.; Savéant, J. -M. Electrodimerization I. One-Electron Irreversible Dimerization. Diagnostic Criteria and Rate Determination Procedures for Voltammetric Studies. J. Electroanal. Chem. 1970, 26, 147-186.

53. Ammar, F.; Nadjo, L.; Savéant, J.-M. Linear Sweep Voltammetry: Kinetic Control by Charge Transfer and/or Secondary Chemical Reactions: II. Reduction of Carbonyl Compounds. J. Electroanal. Chem. 1973, 48, 146-149.

54. Amatore, C.; Gareil, M.; Savéant, J.-M. Homogeneous vs. Heterogeneous Electron Transfer in Electrochemical Reactions: Application to the Electrohydrogenation of Anthracene and Related Reactions. J. Electroanal. Chem. 1983, 147, 1-38. 
55. Chen, Q.-S.; Solla-Gullón, J.; Sun, S.-G.; Feliu, J.M. The Potential of Zero Total Charge of Pt Nanoparticles and Polycrystalline Electrodes with Different Surface Structure: The Role of Anion Adsorption in Fundamental Electrocatalysis. Electrochim. Acta 2010, 55, 7982-7994.

56. Angerstein-Kozlowska, H.; Conway, B. E.; Sharp, W. B. A. The Real Condition of Electrochemically Oxidized Platinum Surfaces. Part I. Resolution of Component Processes. J. Electroanal. Chem. Interfacial Electrochem. 1973, 43, 9-36.

57. Perry, S. C.; Denuault, G. Transient Study of the Oxygen Reduction Reaction on Reduced Pt and Pt Alloys Microelectrodes: Evidence for the Reduction of Pre-Adsorbed Oxygen Species Linked to Dissolved Oxygen. Phys. Chem. Chem. Phys. 2015, 17, 30005-30012.

58. Perry, S.C.; Denuault, G. The Oxygen Reduction Reaction (ORR) on Reduced Metals: Evidence for a Unique Relationship between the Coverage of Adsorbed Oxygen Species and Adsorption Energy. Phys. Chem. Chem. Phys. 2016, 18, 10218-10223.

59. Angerstein-Kozlowska, H.; Conway, B. E. Evaluation of Rate Constants and Reversibility Parameters for Surface Reactions by the Potential-Sweep Method. J. Electroanal. Chem. 1979, 95, 1-28.

60. Fried, I.; Elving, P. J. The Rotating Disk Electrode. Effect of Rates of Rotation and Polarization. Anal. Chem. 1965, 37, 803-806.

61. Andricacos, P. C.; Cheh, H. Y. The Application of Linear Sweep Voltammetry to a Rotating Disk Electrode for the Reversible Deposition of an Insoluble Species. J. Electrochem. Soc. 1980, 127, 2153-2157.

62. Andricacos, P. C.; Cheh, H. Y. The Application of Linear Sweep Voltammetry to a Rotating Disk Electrode for a Reversible Reaction with Soluble Product. J. Electrochem. Soc. 1980, 127, 2385-2388.

63. Andricacos P. C.; Cheh, H. Y. The Application of Linear Sweep Voltammetry to a Rotating Disk Electrode for a First-Order Irreversible Reaction. J. Electroanal. Chem. 1981, 124, 95-101.

64. Quintana, G. C.; Andricacos, P. C.; Cheh, H. Y. Linear Sweep Voltammetry at a Rotating Disk Electrode for First-Order Quasi-Reversible Reactions. J. Electroanal. Chem. 1983, 144, 77-85.

65. Levich V. G., Physicochemical Hydrodynamics, Prentice-Hall, Englewood Cliffs, NJ, 1962. 
66. Britz, D. Digital Simulation in Electrochemistry, 3rd ed.; Springer, Heidelberg, 2005.

67. Strutwolf, J. Schooller, W.W. Linear and Cyclic Sweep Voltammetry at a Rotating Disk Electrode. A Digital Simulation. Electroanal. 1996, 8, 1034-1039.

68. Conway. B. E. Electrochemical Oxide Film Formation at Noble Metals as a SurfaceChemical Process. Prog. Surf. Sci. 1995, 49, 331-452.

69. Lovric, M.; Osteryoung, J. Linear Scan Voltammetry at Rotating Disk Electrodes. J. Electroanal. Chem. 1986, 197, 63-75.

70. Pasti, I. A.; Gavrilov, N. M.; Mentus, S. V. Potentiodynamic Investigation of Oxygen Reduction Reaction on Polycrystalline Platinum Surface in Acidic Solutions: the Effect of the Polarization Rate on the Kinetic Parameters. Int. J. Electrochem. Sci. 2012, 7, 11076-11090.

71. Hodnik, N.; Baldizzone, C.; Zeradjanin, A.; Mayrhofer, K. J. J. The Effect of the Voltage Scan Rate on the Determination of the Oxygen Reduction Activity of Pt/C Fuel Cell Catalyst. Electrocatal. 2015, 6, 237-241.

72. Gómez-Marín, A. M.; Rizo, R.; Feliu, J. M. Some Reflections on the Understanding of the Oxygen Reduction Reaction at Pt(111). Beilstein J. Nanotechnol. 2013, 4, 956-967.

73. Gómez-Marín, A. M.; Feliu, J. M. Oxygen Reduction on Platinum Single Crystal Electrodes. K. Wandelt. Reference Module in Chemistry, Molecular Sciences and Chemical Engineering. Encyclopedia of Interfacial Chemistry: Surface Science and Electrochemistry, Elsevier, 2018 pp. 820-830.

74. Omura, J.; Yano, H.; Watanabe, M.; Uchida, H. Electrochemical Quartz Crystal Microbalance Analysis of the Oxygen Reduction Reaction on Pt-Based Electrodes. Part 1: Effect of Adsorbed Anions on the Oxygen Reduction Activities of $\mathrm{Pt}$ in $\mathrm{HF}, \mathrm{HClO}_{4}$, and $\mathrm{H}_{2} \mathrm{SO}_{4}$ Solutions. Langmuir 2011, 27, 6464-6470.

75. Katsounaros, I.; Schneider, W. B.; Meier, J. C.; Benedikt, U.; Biedermann, P. U.; Auer, A. A.; Mayrhofer, K. J. J. Hydrogen Peroxide Electrochemistry on Platinum: Towards Understanding the Oxygen Reduction Reaction Mechanism. Phys. Chem. Chem. Phys. 2012, 14, 7384-7391.

76. Briega-Martos, V.; Herrero, E.; Feliu, J. M. The Inhibition of Hydrogen Peroxide Reduction at Low Potentials on Pt(111): Hydrogen Adsorption or Interfacial Charge? Electrochem. Commun. 2017, 85, 32-35.

77. Yeager, E. Dioxygen Electrocatalysis: Mechanisms in Relation to Catalyst Structure, $J$. Mol. Catal. 1986, 38, 5-25. 
78. Yeager, E. Electrocatalysts for $\mathrm{O}_{2}$ Reduction, Electrochim. Acta 1984, 29, 1527-1537.

79. Jirkovsky, J. S.; Halasa, M.; Schiffrin, D. J. Kinetics of Electrocatalytic Reduction of Oxygen and Hydrogen Peroxide on Dispersed Gold Nanoparticles. Phys. Chem. Chem. Phys. 2010, 12, 8042-8052.

80. Divisek, J.; Kastening, B. Electrochemical Generation and Reactivity of the Superoxide Ion in Aqueous Solutions. J. Electroanal. Chem. 1975, 65, 603-621.

81. Eggins, B.R. Detection of Electrochemically Generated Intermediates by Variable Sweep Rate Cyclic Voltammetry. Faraday Discuss. Chem. Soc. 1973, 56, 276-284.

82. Bruckenstein, S.; Feldman, G.A. Radial Transport Times at Rotating Ring-Disk Electrodes. Limitations on the Detection of Electrode Intermediates Undergoing Homogeneous Chemical Reactions. J. Electroanal. Chem. 1965, 9, 395-399.

83. Prater, K.B.; Bard, A.J. Rotating Ring-Disk Electrodes III. Catalytic and ECE Reactions. J. Electrochem. Soc. 1970, 117, 1517-1520.

84. Prater, K.B.; Bard, A.J. Rotating Ring-Disk Electrodes II. Digital Simulation of First and Second-Order Following Chemical Reactions. J. Electrochem. Soc. 1970, 117, 335-340.

85. Shen, Y.; Traüble, M.; Wittstock, G. Detection of Hydrogen Peroxide Produced during Electrochemical Oxygen Reduction using Scanning Electrochemical Microscopy. Anal. Chem. 2008, 80, 750-759.

86. Sánchez-Sánchez, C. M.; Bard, A. J. Hydrogen Peroxide Production in the Oxygen Reduction Reaction at Different Electrocatalysts as Quantified by Scanning Electrochemical Microscopy. Anal. Chem. 2009, 81, 8094-8100.

87. Malachesky, P. A.; Marcoux, L. S.; Adams, R. N. Homogeneous Chemical Kinetics with the Rotating Disk Electrode. J. Phys. Chem. 1966, 70, 4068-4070.

88. Karp, S. Homogeneous Chemical Kinetics with the Rotating Disk Electrode. The ECE Mechanism. J. Phys. Chem. 1968, 72, 1082.

89. Marcoux, L. S.; Adams, R. N.; Feldberg, S. W. Dimerization of Triphenylamine Cation Radicals. Evaluation of Kinetics using the Rotating Disk Electrode. J. Phys. Chem. 1969, 73, 2611-2614.

90. Compton, R. G.; Harland, R. G.; Unwin, P. R.; Waller, A. M. Rotating-Disc Electrodes ECE and DISP1 Processes. J. Chem. Soc. Faraday Trans. 1 1987, 83, 1261-1268.

91. Compton, R.G.; Unwin, P.R. Rotating-Disc Electrode Voltammetry. Digital Simulation of the Current-Voltage Behaviour of Electrode Processes Involving Reversible Electron- 
Transfer and Coupled Homogeneous Kinetics. J. Chem. Soc. Faraday Trans. 1 1989, 85, 1821-1834.

92. Vargas, R.; Borrás, C.; Mostany, J.; Scharifker, B.R. Kinetics of Surface Reactions on Rotating Disk Electrodes. Electrochim. Acta 2012, 80, 326-333.

93. Pletcher, D.; Sotiropoulos, S. A Study of Cathodic Oxygen Reduction at Platinum Using Microelectrodes. J. Electroanal. Chem. 1993, 356, 109-119.

94. Amatore, C.; Pinson, J.; Savéant, J. M.; Thiebault, A. Trace Crossings in Cyclic Voltammetry and Electrochemic Electrochemical Inducement of Chemical Reactions: Aromatic Nucleophilic Substitution. J. Electroanal. Chem. 1980, 107, 59-74.

95. Sawyer, D.T.; Seo, E.T. One-electron Mechanism for the Electrochemical Reduction of Molecular Oxygen. Inorg. Chem. 1977, 16, 499-501.

96. Nørskov, J.; Rossmeisl, J.; Logadottir, A.; Lindqvist, L. Origin of the Overpotential for Oxygen Reduction at a Fuel-Cell Cathode J. Phys. Chem. B 2004, 108, 17886-17892.

97. Chen, J.; Fang, L.; Luo, S.; Liu, Y.; Chen, S. Electrocatalytic $\mathrm{O}_{2}$ Reduction on Pt: Multiple Roles of Oxygenated Adsorbates, Nature of Active Sites, and Origin of Overpotential. J. Phys. Chem. C 2017, 121, 6209-6217.

98. Airey, P.L.; Sutton, H.C. Electrochemistry of the $\mathrm{HO}_{2}$ and $\mathrm{O}_{2}{ }^{-}$Radicals under Steady State Conditions Part 2.-The Effect of $\mathrm{pH}$ over the Range 0.4 to 11. J. Chem. Soc. Faraday Trans. 1 1976, 72, 2452-2461.

99. Martínez-Hincapié, R.; Berná, A.; Rodes, A.; Climent, V.; Feliu, J. M. Surface Acid-Base Properties of Anion Adsorbed Species at Pt(111) Electrode Surfaces in Contact with $\mathrm{CO}_{2}$ Containing Perchloric Acid Solutions. J. Phys. Chem. C 2016, 120, 16191-16199.

100. Tian, F.; Anderson, A.B. Effective Reversible Potential, Energy Loss, and Overpotential on Platinum Fuel Cell Cathodes. J. Phys. Chem. C 2011, 115, 4076-4088.

101. Walch. S.P. Effect of Solvation on the Oxygen Reduction Reaction on Pt Catalyst. $J$. Phys. Chem. C 2011, 115, 7377-7391.

102. Balbuena, P. B.; Salazar, P. F.; Seminario, J. M. Adsorption and Dissociation of $\mathrm{H}_{2} \mathrm{O}_{2}$ on Pt and Pt-Alloy Clusters and Surfaces. J. Phys. Chem. B 2006, 110, 17452-17459.

103. Behar, D.; Czapski, G.; Rabani, J.; Dorfman, L. M.; Schwarz, H. A. The Acid Dissociation Constant and Decay Kinetics of the Perhydroxyl Radical. J. Phys. Chem. 1970, 74, 3209-3213.

104. Blelski, B. H. J.; Allen, A. O. Mechanism of the Disproportionation of Superoxide Radicals. J. Phys. Chem. 1977, 81, 1048-1050. 
105. Breiter, M. W. Voltammetric Study of the Reduction of Molecular Oxygen on Bright Platinum in Perchloric Acid Solution. Electrochim. Acta 1964, 9, 441-450.

106. McIntyre, J. D. E. The Kinetics of Electrode Processes with Coupled Heterogeneous Chemical Catalytic Reactions. J. Phys. Chem. 1967, 71, 1196-1207.

107. McIntyre, J. D. E. The Kinetics of Heterogeneous Catalytic Electrode Reactions. II. Charge-Transfer Kinetics. J. Phys. Chem. 1969, 73, 4102-4110.

108. McIntyre, J. D. E. On the Distinction between the Kinetics of Parallel and Heterogeneous Catalytic Electrode Reactions. J. Phys. Chem. 1969, 73, 4111-4115.

109. Blurton, K.F.; McMullin, E. The Cathodic Reduction of Oxygen on Platinum in Alkaline Solutions. J. Electrochem. Soc. 1969, 116, 1476-1480.

110. Adanuvor, P.K.; White, R.E. Simulation of the Polarization Curves for Oxygen Reduction at a Rotating Disk Electrode. J. Electrochem. Soc. 1987, 134, 1093-1098. 


\section{TOC Graphic}

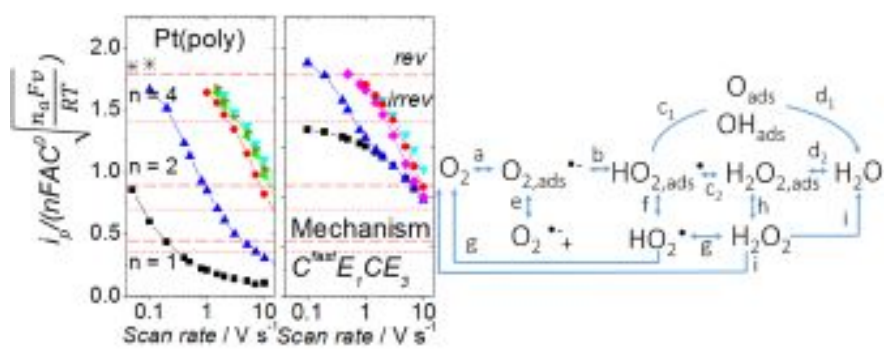

